\title{
Effect of grain boundary precipitation on the mechanical integrity of EBW joints of Inconel 625
}

K. Devendranath Ramkumar a, ${ }^{*}$, Sachet Sangamesh Mulimani a, Kumar Ankit a, Ankita Kothari a, Supriyo Ganguly b

a School of Mechanical Engineering, Vellore Institute of Technology, Vellore - 632014

b Cranfield University, Bedfordshire, United Kingdom

Corresponding Author, E-mail: devendranathramkumar@gmail.com

\begin{abstract}
The precipitation effects on the mechanical behavior of electron beam welded joints of Inconel 625 in the as-welded [AW] and post-weld heat treatment [PWHT] conditions have been investigated in this research study. A PWHT comprising of direct aging [DA] treatment at $700{ }^{\circ} \mathrm{C}$ for $100 \mathrm{~h}$ in vacuum at a pressure of $10^{-5} \mathrm{mbar}$ was performed on the weld joints. The microstructure of the base alloy opined the precipitation of MC system carbides and $\gamma^{\prime \prime}$ strengthening phase after subjecting to DA. Also, Nb-Mo rich precipitates and the Laves phase was noticed in the inter-dendritic arms of the fusion zone (FZ) of welded joints in the AW conditions. DA treatment has a notable effect on the weld mechanical characteristics of Inconel 625 joints. The precipitation of $\gamma^{\prime \prime}$ strengthening phase is reasoned for the significant rise in the yield strength [YS] and tensile strength [TS] of the base alloy and EBW joints.
\end{abstract}

\section{Keywords: Inconel 625; Electron beam welding; post-weld heat treatment; microstructure; tensile strength}

\subsection{Introduction}

A nickel-based, solid solution strengthened super-alloy Inconel 625 has been widely used in aerospace, marine, geothermal, nuclear industries. Alloy 625 offers outstanding mechanical properties combined with corrosion resistance at high temperatures. Alloy 625 is widely recommended as a cladding material in the industries, layered on carbon steels and stainless steels to enhance the corrosion resistance at high temperatures. The 
additions of $\mathrm{Nb}, \mathrm{Mo}$, and $\mathrm{Ti}$ in this alloy impart mechanical strength both in the room and elevated temperature conditions. Further, this alloy 625 also exhibits better weldability and fabricability and hence receives major attraction in these industries [1].

Some attempts have been made in the recent past to investigate the influence of the welding process on the structure-property relationships of Ni-based super-alloys. Han et al. [2] demonstrated the significance of $\mathrm{Nb}$ content on the pitting corrosion resistance of Inconel 625 welds obtained from shielded metal arc welding (SMAW). The researchers notified that there was no considerable improvement in the corrosion resistance except a trivial rise in hardness values while increasing the $\mathrm{Nb}$ content. According to the results, a higher degree of sensitization was observed in Inconel 625 welds with the $\mathrm{Nb}$ content of $2.24 \mathrm{wt} \%$. Many researchers attested that the use of high heat input welding results in micro-fissuring or liquation cracking at the heat-affected zone (HAZ), segregation in the inter-dendritic arms, and weld residual stresses. Hence, the high energy density processes namely electron beam welding (EBW) and laser beam welding (LBW) have been recommended by the industries to overcome the aforementioned problems.

In a study, tubular joints of dissimilar Ni-based alloys namely Inconel 600 and Inconel 690 , used in nuclear industries were developed using Nd: YAG laser welding by Kim et al. [3]. Though the authors obtained the dissimilar Inconel welds without any hot cracking, they observed a higher tensile residual stress in the fusion zone (FZ). Jelokhani-Niaraki et al. [4] optimized the process parameters such as welding speed, power, and the spot size during laser welding of Inconel 625 using the response surface methodology (RSM) technique. The authors concluded that the use of high laser power not only increases the depth of penetration; but also resulted in a high volume fraction of the Laves phase and higher susceptibility to cracking. Janicki [5] employed the fiber laser welding technique to join $0.8 \mathrm{~mm}$ thick Inconel 625. The authors observed an average tensile strength of 887 MPa as weld strength of laser weld joints of Inconel 625. However, there were no detailed microscopy investigations reported by the authors on these weld seams.

EBW is a versatile, high energy density process and efficient in welding components of greater thickness in a single pass. The significant advantages of EBW over other welding techniques are lesser heat input, reduced or nil HAZ, a high depth to width ratio, and low enduring stress in the weld seams. Most of the research works have been focused on utilizing EBW to achieve dissimilar weld joints involving Inconel 625 and various grades 
of stainless steel. Devendranath et al. [6] had employed EB welding for joining dissimilar alloys between Inconel 625 and DSS 2205 and similarly, Shakil et al. [7] conducted the studies on the dissimilar joints Inconel 625 and AISI 304L. Wiednig et al. [8] successfully demonstrated the EBW process for obtaining dissimilar joints involving Inconel 625 and 9\% $\mathrm{Cr}$ steel alloys of $50 \mathrm{~mm}$ thick in a single pass. In the recent past, Romanin et al. [9] investigated the EBW of $2.5 \mathrm{~mm}$ thick sheets of Inconel 625. The authors had primarily focussed on the metallurgical aspects at the FZ of the EBW joint and also carried out the non-linear thermal transient analysis of the EBW process.

Although Inconel 625 is a solid-solution hardened and readily weldable alloy, this alloy could be affected by the formation of MC system carbides such as MC, $\mathrm{M}_{23} \mathrm{C}_{6}$, $\gamma^{\prime \prime}$ and other intermetallic phases developed at $550-750^{\circ} \mathrm{C}$ as stated by Radavich and Fort [10]. The formation of these MC system carbides and the strengthening $\gamma^{\prime \prime}$ phase largely depends on the aging temperature and time. The precipitation of $\gamma^{\prime}$ and $\gamma^{\prime \prime}$ is strongly dependent on the quantities of alloying elements $\mathrm{Nb}, \mathrm{Mo}, \mathrm{Al}$, and Ti respectively. Shaikh et al. [11] observed the precipitation of $\gamma^{\prime \prime}$ precipitates when aged at $700^{\circ} \mathrm{C}$ for $144 \mathrm{~h}$. The authors attested that the nucleation of $\gamma^{\prime \prime}$ precipitates happened heterogeneously on defects like stacking faults, dislocations, and twin boundaries. Sims et al. [12] concluded that the precipitation of $\gamma^{\prime \prime}$ in the grains and the formation of $\mathrm{M}_{23} \mathrm{C}_{6}$ carbides alongside the grain boundaries resulted in amelioration of the mechanical properties of Ni-based super-alloy. Cortial et al. [13] carried out the industrial type heat treatments between $600^{\circ} \mathrm{C}$ and $1000^{\circ} \mathrm{C}$ on the microstructure and mechanical characteristics of Inconel 625 alloy welds. The corrosion resistance in sea-water and chloride environments of the heat-treated Inconel 625 weld alloys was also investigated in this study. Song and Nakata [14] performed a comparative study on the metallurgical characteristics and structural integrity of friction stir welds of Inconel 625 alloy in the AW and PWHT conditions. These researchers noticed the existence of $\gamma^{\prime \prime}$ and $\mathrm{M}_{23} \mathrm{C}_{6}$ carbides in the grains of the base alloy and $\gamma^{\prime \prime}$ and $\mathrm{M}_{6} \mathrm{C}$ carbide in the friction stir zone after subjecting to PWHT. These precipitates have considerably improved the YS and TS of the FSW joints of Inconel 625.

It is affirmed from the available literature sources that the tensile characteristics and notch impact toughness of EBW joints in the AW and PWHT conditions have not been thoroughly addressed. Hence, a study has been taken up to perform EBW for achieving 5 $\mathrm{mm}$ thick plates of Inconel 625 joints. Further, a PWHT at $700{ }^{\circ} \mathrm{C}$ for $100 \mathrm{~h}$ in vacuum at 
a pressure of $10^{-5}$ mbar was performed on the EBW seams. The metallurgical and mechanical characterization was carried out on the EBW seams of Inconel 625 in both conditions.

\subsection{Experimental work}

Rectangular specimens of size $200 \times 55 \times 5 \mathrm{~mm}$ were machined from the hot-rolled Inconel 625 alloy using numerically controlled electric discharge machining using Mo wire. The composition of elements present in the base alloy has been investigated and provided in Table 1. The specimens to be welded were surface ground using emery sheets, properly cleaned using acetone to eliminate the oxides and other contaminants. Square butt configuration was maintained to autogenously weld Inconel 625 plates by a single pass, EBW process. The specifications employed for EBW of Inconel 625 alloy plates are given in Table 2. The welding speed was maintained at $25 \mathrm{~mm} / \mathrm{s}$ with an accelerating voltage of $60 \mathrm{kV}$. Welding was carried out according to the process parameters mentioned in Table 2 in a vacuum chamber level with a pressure level of 104 to $10^{-5}$ mbar. The plates to be welded were first clamped and then tacked at the ends to avoid distortion. After welding, the EBW seams were examined using the X-ray radiography technique to explore the weld quality in terms of surface/sub-surface flaws. The test results indicated that the process parameters were adequate to obtain EBW joints with full-penetration and also free from any weld defects. To investigate the precipitation behavior, the EBW joints of Inconel 625, a post-heat treatment comprising of heating the joints at $700^{\circ} \mathrm{C}$ (heated up $10^{\circ} \mathrm{C} / \mathrm{min}$. from room temperature) for $100 \mathrm{~h}$ in the vacuum of $10^{-5} \mathrm{mbar}$. Then the heat-treated samples were then furnace cooled from $700^{\circ} \mathrm{C}$ to room temperature. The PWHT adopted in the current study is done based on the earlier works of Song and Nakata [14] for FSW joints of Inconel 625.

Metallographic samples of dimensions $28 \times 10 \times 5 \mathrm{~mm}$ from the EBW joints were retrieved transversely concerning the direction of welding as provided in Fig. S1.These samples in the AW and PWHT conditions were subjected to traditional metallographic practices for microstructural investigation. Samples were polished to obtain a mirror-like finish and then etched electrolytically with $10 \%$ oxalic acid using a 6 V DC supply for 15 $20 \mathrm{~s}$. The primary microstructural assessment on both the samples was examined using ZEISS Axio Vert A1 inverted microscope. Further, scanning electron microscopy (SEM) attached with energy dispersive X-ray analysis (EDS) was used to perform the detailed 
characterization of the precipitates and phases. The analysis of phases and the orientation of the grain boundaries in the FZ before and after PWHT were investigated using electron backscatter diffraction (EBSD) analysis.

Cross-sectional, surface micro-indentation studies were performed on the EBW joints covering all the regions using Vickers micro-hardness tester. The hardness computations were done on the transversely cut EBW specimens at appropriate intervals of every 0.25 $\mathrm{mm}$ with a test force of $500 \mathrm{gf}$. Further, the performance of the EBW seams both in the AW and PWHT conditions towards tensile loading was investigated on the transverse coupons fabricated under ASTM E8/8M specifications. The tensile test was performed using an Instron Universal Testing Machine operated with a transverse speed of 1 $\mathrm{mm} / \mathrm{min}$. Similarly, the response of the weld seams towards impact loading was established using a Charpy V-notch impact tester. A sudden load was confined to act at the notched region of the EBW joints designed according to ASTM E23:12C standard to investigate the impact behaviour at room temperature. Samples in triplicate were tested in each of these mechanical integrity experiments in both the conditions.

\subsection{Results \& Discussion}

\subsection{Characterization of microstructure}

The microstructure of the base alloy shown in Fig. 1(a) comprises elongated Ni-rich austenitic matrix with the twin boundaries and polygonal-shaped carbides or carbonitrides of $\mathrm{Nb}$ and $\mathrm{Ti}$. Under high magnification, continuous, fine precipitates at the grain boundaries are also recognized [Fig. 1(b)] on the parent metal side of Alloy 625 after subjecting to $100 \mathrm{~h}$ heat treatment. The precipitates have grown along the $\gamma$ matrix grain boundaries of the base alloy region and have typical elliptical morphology. Based on this morphology, these precipitates are identified to be $\gamma^{\prime \prime}$ strengthening phase. Precipitates of similar morphology were reported by Malej et al. [15] during thermal aging of Inconel 625 for 25,240 , and $504 \mathrm{~h}$. Similarly, in the base alloy region, a large number of twins appeared and also have fine precipitates at twin boundaries. The authors believe that these fine precipitates along the twin boundaries are probably $\mathrm{M}_{23} \mathrm{C}_{6}$ secondary carbides and $\gamma$ " phase.

X-ray radiography technique confirmed that the EB weld seams of Inconel 625 were free from any welding defects including the micro-fissures or cracks. The weld shape of 
Inconel 625 was analyzed using the cross-sectional macrostructural image provided in Fig. 2(a) and 2(b). Full penetration without defects indicates that the process specifications adopted in the research are appropriate. Interface microstructures of the EBW seams in the AW and PWHT conditions are shown in Fig. 3(a) and 3(b). It is opined from Fig. 3 that no major microstructural changes are noticed except the precipitation of grain boundary carbides across the interface after aging for $100 \mathrm{~h}$.

Columnar dendrites were observed in the FZ of EBW joints along with the microsegregation in the inter-dendritic zones as evident from the EDS analysis depicted in Fig. 4(a). The compositional changes across the dendrite and inter-dendritic zones of the EBW joints in the AW conditions could be observed clearly from the EDS data provided in Fig. 4(b). Further, it is revealed from the EDS spectra that these segregated precipitates are richer in $\mathrm{Nb}, \mathrm{Mo}$, and $\mathrm{Si}$ and lean in $\mathrm{Fe}, \mathrm{Cr}$ compared to the composition of the base alloy. These richer elemental constituents in the segregate indicate the occurrence of the Laves phase and $\sigma$ phase in the AW conditions. It is opined that the $\mathrm{Nb}$ segregation is essential for the occurrence of the solidification phase and there is very limited segregation of Ti to the Laves phase. The results are in agreement with Chen et al. [16].

As stated by DuPont et al. [17], the dendritic cores of austenite that originate at the initial stages of solidification phenomena are depleted of $\mathrm{Nb}$ and Mo. Hence, the precipitates of Mo and $\mathrm{Nb}$ will form preferably in the inter-dendritic areas by the eutectic reaction, only after the molten liquid becomes richer in $\mathrm{Nb}$ and Mo. EBSD analysis across the EB weld zone in the AW condition shown in Fig. 5 confirmed the occurrence of Mo rich $\sigma$-phase and the precipitation of MC system carbides such as $\mathrm{M}_{23} \mathrm{C}_{6}, \mathrm{M}_{6} \mathrm{C}$ across the grain boundaries. The histogram shown in Fig. 6 indicates the FZ is prevailed to have $\sim 75-80 \%$ high angle grain boundaries (HAGs) of the entire grain misorientation angle distribution. A similar trend was observed by Sujai and Devendranath Ramkumar [18] during EB welding of Incoloy 925.

It is noticed from Fig. 7(a) that the complete dissolution of the Laves phase has not occurred even after subjecting to a solutionizing and aging treatment for $700^{\circ} \mathrm{C}$ for $100 \mathrm{~h}$. This is because the dissolution of the Laves phase is relatively hard to achieve on account of the poor diffusivity of $\mathrm{Nb}$ atoms as claimed by Janakiram et al. [19]. However, the aging temperature and time are found to be sufficient to achieve the 
precipitation of $\gamma^{\prime \prime}$ strengthening phase in the base alloy and the FZ along with the occurrence of MC system carbides. After subjecting to the prolonged aging, trivial grain growth is noticed in the weld zone microstructure and is confirmed by the EBSD analysis. SEM/EDS analysis provided in Fig. 7(b) elucidates the evolution of Ti-rich carbides/carbo-nitrides and scarce, needle-shaped $\delta$ - $\mathrm{Ni}_{3} \mathrm{Nb}$ in the $\mathrm{FZ}$ after subjecting to $100 \mathrm{~h}$ aging. According to Suave et al. [20], the precipitation domain of the $\delta-\mathrm{Ni}_{3} \mathrm{Nb}$ phase is approximately 650 to $900^{\circ} \mathrm{C}$ after prolonged aging time. However, the existence of $\delta$ phase could be noticed scarcely in the grain boundaries of the $\mathrm{FZ}$ along with $\mathrm{M}_{23} \mathrm{C}_{6}$ and $\mathrm{M}_{6} \mathrm{C}$ carbides. EBSD analysis shown in Fig. 8 also confirmed the existence of these carbides along with the traces of $\sigma$-phase. As pointed out by DuPont et al. [17], the $\sigma$ phase form is recognized to occur as a product of solid-state precipitation when exposed for longer times at lower temperatures. It is also to be noted that the stability of $\sigma$-phase increases with a decrease in temperature. Furthermore, the $\sigma$-phase is not stable at temperatures above $1000^{\circ} \mathrm{C}$. On the other hand, aging at higher temperatures above $900^{\circ} \mathrm{C}$ will result in grain growth as evident from Fig. 9, and excessive precipitation, which consequently lowers the mechanical characteristics. Hence, an optimal aging temperature is utilized in contemporary work. The histogram displayed in Fig. 9 also indicates the amount of low angle grain boundaries (LAGs) and HAGs are modified as $\sim 35 \%$ and $\sim 65 \%$ after subjected to PWHT. As reported by Trillo and Murr [21], the range of low angle boundaries depend on the composition of the alloy, heat treatment conditions, and the type of precipitates. The concentration of low angle grain boundary (LAGB) is a measure of the magnitude degree of local deformation or the residual stresses internally [22]. Further, the authors reported that the LAGBs or residual stresses serve as the driving force for remarkable microstructural changes (recrystallization).

\subsection{Mechanical property evaluation}

The changes in the micro-hardness values before and after direct aging are presented in Fig. 10 and Table 3. The average micro-hardness values of base alloy Inconel 625 side before and after direct aging was revealed to be $266 \mathrm{HV}$ and $388 \mathrm{HV}$ respectively. Similarly, the average hardness value of the EB weld zone was increased from $246 \mathrm{HV}$ to $334 \mathrm{HV}$ after subjected to direct aging treatment. The study attests that both the base alloy side and EB weld joints of Inconel 625 imparts a significant rise in hardness to $45.67 \%$ and $35.77 \%$ respectively after $100 \mathrm{~h}$ of aging treatment. The substantial increase 
in the hardness of the base alloy after thermal aging could be reasoned to the precipitation of $\gamma^{\prime \prime}$ strengthening phase. The formation of $\mathrm{M}_{23} \mathrm{C}_{6}, \mathrm{M}_{6} \mathrm{C}$ carbides have also been favored in increasing the hardness of the base alloy and weld region, which is attested from EBSD analysis. Similar hardness trends were noticed during the friction stir welding of Inconel 625 welds served by Song and Nakata [14]. The convection phenomena of the weld zone along with the divergence in the supersaturation of strengthening elements $\mathrm{Mo}$ and $\mathrm{Nb}$ in the $\gamma$-matrix are attributing to the decline or scatter trend of hardness values in the FZ.

Tensile test results of both the welded and aged EBW joints of Inconel 625 are shown in Fig. 11(a) and the data are listed in Table 4. The tensile properties of the joints are following the hardness trends in both conditions. The base alloy Inconel 625 demonstrated a UTS of $879 \mathrm{MPa}$ and $1111 \mathrm{MPa}$ in the as-received and DA conditions respectively. The YS and TS of the base alloy were increased to $60.37 \%$ and $26.25 \%$ respectively after subjecting to direct aging. The increase in both strengths could be attributed to the precipitation of $\gamma^{\prime \prime}$ strengthening phase in the base alloy. On the other hand, the tensile elongation was lowered from $53.5 \%$ to $34 \%$ after direct aging. The precipitation of grain boundary carbides $\mathrm{M}_{6} \mathrm{C}$ and $\mathrm{M}_{23} \mathrm{C}_{6}$ contributed significantly to the reduction in the tensile elongation of the base alloy. It is well acknowledged that $\mathrm{M}_{23} \mathrm{C}_{6}$ carbide is highly brittle and there will be a lesser bond strength between the $\mathrm{M}_{23} \mathrm{C}_{6}$ and matrix. Before subjecting to the aging treatment, the grains in the matrix are connected well through grain boundaries. However, the grains are parted by the coarse $\mathrm{M}_{23} \mathrm{C}_{6}$ and MC system carbides after aging treatment. Hence during the tensile test, when the stress level reaches maximum, the carbide breaks first and cracks are generated at the grain boundaries. Similar trend in the tensile properties was observed by Hu et al. [23].

When subjecting to tensile loads, the failures emerged in the FZ of the EBW joints in both conditions. The tensile strength of the EBW joint was increased from $858 \mathrm{MPa}$ to 1,011 MPa after exposed to DA treatment. The YS of the EBW joints was also considerably improved from 565 MPa to 671.5 MPa. A higher YS of the joints is mainly derived from the $\gamma^{\prime \prime}$ strengthening phase and $\mathrm{Ni}_{2}(\mathrm{Cr}, \mathrm{Mo})$ in the matrix while exposing in the elevated temperature, as stated by Shankar et al. [24]. The joint efficiencies imparted by the EB weld joints of Inconel 625 are 97.53\% and 90.99\% in the AW and DA conditions respectively. In addition to the $\mathrm{M}_{23} \mathrm{C}_{6}$ carbide precipitation, the occurrence of the Laves 
phase and needle-shaped $\delta$ phase also marginally lowered the TS values of the EBW joints as compared to the base alloy in the aged conditions. Both the $\delta$ and Laves phases rely upon the diffusion of $\mathrm{Nb}$ and the kinetics of both the phases are approximately the same. As observed from the microstructural studies, these brittle phases formed in the interdendritic regions. The areas adjacent to these $\delta$ and Laves particles may be sufficiently depleted in $\mathrm{Nb}$ to retard the formation of $\gamma^{\prime \prime}$. The presence of denuded zones at the grain boundaries is often associated with the deterioration of tensile strength of Inconel 625 [1]. The tensile elongation has marginally dropped while testing the weld joints after exposed to PWHT. FE-SEM images of the fractured tensile samples of EBW joints of both the AW and PWHT conditions are shown in Fig. 11(b) and 11(c) respectively. The micro-voids and dimples are dominated in the FZ of the AW condition, which, in turn, indicated the ductile mode of fracture. The occurrence of scarce, fine Laves particles in the inter-dendritic zones of the FZ and the subsistence of MC system carbides favored in the initiation of micro-voids/cracks on the Laves/matrix interfaces in the AW conditions. Meanwhile, the tensile failure was the ductile mode in the DA condition, the fracture mode is trans-granular in nature as evident from Fig. 11(c). The trans-granular dimple fracture of Inconel 625 is resulted due to the co-precipitation of $\delta$ phase and well separated discrete carbides while carrying out aging at temperatures as stated by Sundararaman et al. [25].

Charpy notch impact studies indicated the DA treatment resulted in the loss of toughness of both EBW joints as well as the base alloy. However, the notch impact toughness values of EBW joints are considerably greater than the base alloy. The reduction in the impact toughness in the DA condition is reasoned to the precipitation of $\gamma^{\prime \prime}$ and carbide particles in the base alloy. An increase in impact toughness to $\sim 39 \%$ and $\sim 27 \%$ was observed in the EBW joints in both AW and PWHT conditions compared to the base alloy. It is opined from the notch impact test that the EBW joints experienced a low energy absorption tendency such that the joints were fractured into equal halves upon impact loading, in both cases. A slight increase in the impact toughness of EBW joints compared to the base alloy could be reasoned to the presence of scarce $\gamma^{\prime \prime}$ strengthening phase and MC carbides in the AW conditions, as inferred from the hardness plots shown in Fig. 10. On the other hand, the PWHT has influenced the occurrence of $\gamma^{\prime \prime}$ phase and carbide precipitation in the FZ extensively and lowered the impact toughness of the EBW joints. 
It is observed from the SEM fractography shown in Fig. 12(a) that a higher volume of NbMo rich segregates/ Laves particles in the dendritic arms along which the crack has been propagated. In contrast, the precipitation of the strengthening $\gamma^{\prime \prime}$ phase, $\delta$ phase and MC carbides such as $\mathrm{M}_{23} \mathrm{C}_{6}, \mathrm{M}_{6} \mathrm{C}$ deteriorated the notch toughness of the EBW seams drastically as confirmed from SEM fractography shown in Fig. 12(b). The results are well in agreement with Köhler [26]. It is evident from all these tests that the DA treatment has a remarkable consequence on the mechanical traits of the EBW joints of Inconel 625.

In summary, the study attests to the successful adoption of the EBW process for joining 5 $\mathrm{mm}$ thick Inconel 625 plates. The process specifications chosen in the study are sufficed enough because of the absence of solidification fissures or any weld defects. A systematic and detailed comparison of the weld microstructures in both AW and DA conditions has been attempted. The mechanical property investigations are also carried out in these conditions. The precipitation of MC system carbides, Laves particles, strengthening $\gamma^{\prime \prime}$ phase, $\delta$-phase-in $\gamma$ matrix and their role in modifying the mechanical properties are elaborated in the studies.

\subsection{Conclusions}

In reference to the specific process parameters and conditions adopted in the EBW of Inconel 625, the outcomes drawn from the studies are as follows:

[1] The high energy density EB welding process is highly recommended for establishing the weld seams of Inconel 625, which are free from solidification fissures and hot cracks.

[2] Micro-segregation of Mo-rich and Laves phases was observed in the FZ in the aswelded conditions. The precipitation of strengthening $\gamma^{\prime \prime}$, MC system carbides such as $\mathrm{M}_{23} \mathrm{C}_{6}, \mathrm{M}_{6} \mathrm{C}$ along with the partial dissolution of the Laves phase was noticed after subjecting to PWHT. The needle-shaped $\delta$ - $\mathrm{Ni}_{3} \mathrm{Nb}$ in the FZ was beginning to precipitate after $100 \mathrm{~h}$ exposure at $700^{\circ} \mathrm{C}$.

[3] Both the base alloy and EB weld joints of Inconel 625 imparted a significant rise in hardness to $45.67 \%$ and $35.77 \%$ respectively after $100 \mathrm{~h}$ of aging treatment.

[4] Upon tensile loading, the failures took place in the FZ of EBW joints. The joint efficiencies exhibited by the EB welded joints were $97.53 \%$ and $90.99 \%$ before 
and after PWHT. Both the YS and TS of the base alloy were increased to $60.37 \%$ and $26.25 \%$ respectively after subjecting to direct aging treatment.

[5] The precipitation of $\gamma^{\prime \prime}$ phase, $\delta$ phase and $\mathrm{MC}$ carbides such as $\mathrm{M}_{23} \mathrm{C}_{6}, \mathrm{M}_{6} \mathrm{C}$ deteriorated the notch impact toughness of the EBW seams and the base alloy.

\section{Data Availability Statement}

The raw and processed data are already provided in the manuscript

\section{Acknowledgment}

We would like to thank the Royal Academy of Engineering, UK for the funding provided as a part of the Indo-UK Academia Partnership Programme (IAPP) [IAPP 18/19-161]. The authors wish to thank Mr. M. Agilan, ISRO for his kind support in carrying out EB Welding at Brahmos Aerospace, Trivandrum. We devote our sincere gratitude to Prof. Indradev S. Samajdar, IIT Mumbai for providing the EBSD facility. We would like to acknowledge the FE-SEM, SEM/EDS facilities provided by VIT, Vellore for carrying out the research work. We are indebted to Dr. R. Vasudevan Dean, School of Mechanical Engineering for the staunch support rendering in the execution of this project. Finally, we would like to thank Mr. D. Arun for his continued support in all the stages of this work.

\section{Data Availability Statement}

The raw and processed data are already provided in the manuscript

\section{References}

1. Floreen S, Fuchs GE, Yang WJ. The Metallurgy of Alloy 625 2012:13-37. https://doi.org/10.7449/1994/superalloys_1994_13_37.

2. Han JW, Jung SH, Cho H, Lee HW. Investigation of the weld properties of Inconel 625 based on $\mathrm{Nb}$ content. Int J Electrochem Sci 2018;13:2829-41. https://doi.org/10.20964/2018.03.01.

3. Kim J Do, Kim CJ, Chung CM. Repair welding of etched tubular components of nuclear power plant by Nd:YAG laser. J Mater Process Technol 2001;114:51-6. https://doi.org/10.1016/S0924-0136(01)00566-0.

4. Jelokhani-Niaraki MR, B. Mostafa Arab N, Naffakh-Moosavy H, Ghoreishi M. The systematic parameter optimization in the Nd:YAG laser beam welding of Inconel 625. Int J Adv Manuf Technol 2016;84:2537-46. 
https://doi.org/10.1007/s00170-015-7833-4.

5. Janicki DM. Fiber laser welding of nickel based superalloy Inconel 625. Proc. SPIE 8703, Laser Technology 2012: Applications of Lasers, 87030; 87030R1-R6

6. Devendranath Ramkumar K, Sridhar R, Periwal S, Oza S, Saxena V, Hidad P, et al. Investigations on the structure - Property relationships of electron beam welded Inconel 625 and UNS 32205. Mater Des 2015;68:158-66. https://doi.org/10.1016/j.matdes.2014.12.032.

7. Shakil M, Ahmad M, Tariq NH, Hasan BA, Akhter JI, Ahmed E, et al. Microstructure and hardness studies of electron beam welded Inconel 625 and stainless steel 304L. Vacuum 2014;110:121-6. https://doi.org/10.1016/j.vacuum.2014.08.016.

8. Wiednig C, Lochbichler C, Enzinger N, Beal C, Sommitsch C. Dissimilar electron beam welding of nickel base alloy 625 and 9\% $\mathrm{Cr}$ steel. Procedia Eng 2014;86:184-94. https://doi.org/10.1016/j.proeng.2014.11.027.

9. Romanin L, Ferro P, Fabrizi A, Berto F, et al. A metallurgical and thermal analysis of Inconel 625 electron-beam welded joints. Frattura ed Integrita Strutturale; 2019;13(50);251-263. DOI: 10.3221/IGF-ESIS.50.21

10. Radavich JF, Fort A. In: Loria EA, editor. Superalloys 718, 625, 706 and various derivatives. Warrendale (PA): TMS; 1994. p. 635.

11. Shaikh MA, Ahmad M, Shoaib KA, Akhter JI, Iqbal M. Precipitation hardening in Inconel 625, Materials Science and Technology; 2000;16(2);129-132

12. Sims CT, Stoloff NS, Hagel WC. Superalloys. 2nd ed. New York: Wiley-Interscience; 1987

13. Cortial F, Corrieu J-M, Vernot-Loier C, Heat Treatments Of Weld Alloy 625: Influence On The Microstructure, Mechanical Properties And Corrosion Resistance; Supralloys 718,625,706 and Various Derivatives Edited by E.A. Loria The Minerals, Metals \& Materials Society, 1994

14. Song KH, Nakata K. Effect of precipitation on post-heat-treated Inconel 625 alloy after friction stir welding. Mater Des 2010;31:2942-7. https://doi.org/10.1016/j.matdes.2009.12.020.

15. Malej S, Medved J, Batič B, Tehovnik F, Godec M. Microstructural evolution of inconel 625 during thermal aging. Metalurgija 2017;56:319-22.

16. Chen S, Zhao M, Liang H, Rong L. Microstructure and Mechanical Properties of Electron Beam Welded Alloy J75. J Mater Sci Technol 2014;30:493-8. 
https://doi.org/10.1016/j.jmst.2013.11.011.

17. DuPont, JN, Lippold, JC, Liser, S.D Welding metallurgy and weldability nickel base alloys, A John Wiley \& Sons, INC., Publication, 2009.

18. Sujai S, Devendranath Ramkumar K. Direct aging response on the microstructure and mechanical properties of electron beam welds of Ni-Cr-Fe alloy used in vacuum insulated tubing. J Manuf Process 2020;54:359-73. https://doi.org/10.1016/j.jmapro.2020.03.027.

19. Janaki Ram GD, Venugopal Reddy A, Prasad Rao K, Reddy GM, Sarin Sundar JK. Microstructure and tensile properties of Inconel 718 pulsed Nd-YAG laser welds. J Mater Process Technol 2005;167:73-82. https://doi.org/10.1016/j.jmatprotec.2004.09.081.

20. Suave LM, Bertheau D, Cormier J, Villechaise P, Soula A, Hervier Z, Hamon F, Laigo $\mathrm{J}$, et al. Impact of thermomechanical aging on alloy 625 high temperature mechanical properties, 8th International symposium on superalloys 718 and various derivatives, E. Ott, A. Banik, X. Liu, I. Dempster, K. Heck, J. Anderson, J. Groh, T. Gabb, R. Helmink, A. Wusatowska-Sarnek (ed.), Pittsburgh, TMS (2014), 317-331.

21. Trillo EA, Murr LE. A TEM investigation of M23C6 carbide precipitation behaviour on varying grain boundary misorientations in 304 stainless steels. J Mater Sci 1998;33:1263-71. https://doi.org/10.1023/A:1004390029071.

22. Brewer L, Othon M, Young L, Angeliu T. Misorientation mapping for visualization of plastic deformation via electron back-scattered diffraction; Microsc. Microanal. 2006;12(1);85-91

23. Hu R, Bai G, Li J, Zhang J, Zhang T, Fu H. Precipitation behavior of grain boundary $\mathrm{M}_{23} \mathrm{C}_{6}$ and its effect on tensile properties of $\mathrm{Ni}-\mathrm{Cr}-\mathrm{W}$ based superalloy; Materials Science and Engineering: ; 2012; 548; 83-88

24. Shankar V, Bhanu Sankara Rao K, Mannan SL. Microstructure and mechanical properties of Inconel 625 superalloy. J Nucl Mater 2001;288:222-32. https://doi.org/10.1016/S0022-3115(00)00723-6.

25. Sundararaman M, Mukhopadhyay P, Banerjee S. Carbide Precipitation in Nickel Base Superalloys 718 and 625 and Their Effect on Mechanical Properties 2012:367-78. https://doi.org/10.7449/1997/superalloys_1997_367_378.

26. Kohler M. Effect of the Elevated-Temperature-Precipitation in Alloy 625 on 
Properties

and

Microstructure

2012:363-74.

https://doi.org/10.7449/1991/superalloys_1991_363_374.

\section{List of Figures}

Fig. 1 Microstructure of the base alloy Inconel 625 in the (a) as-received and (b) after subjecting to direct aging treatment respectively

Fig. 2 Cross-sectional macrographs showing the EB weld seams of Inconel 625

Fig. 3 SEM images showing the interface microstructures of EBW seams of Inconel 625 in the (a) as-welded and (b) direct aged conditions

Fig. 4 FESEM images showing (a) columnar dendrites and inter-dendrites and (b) Microsegregation of $\mathrm{Nb}$-Mo rich phases in the inter-dendritic regions at the fusion zone of EB welds of Inconel 625 in the as-welded condition

Fig. 4(b) EDS analysis showing the elemental composition at different spots in the fusion region of EB welded Inconel 625 in the as-welded condition

Fig. 5 EBSD analysis depicting (a) Original (b) IPF and (c) Phase map on the weld region of Incoloy 625 joints in the as-welded condition

Fig. 6 EBSD analysis showing (a) average grain size and (b) misorientation angle distribution in the fusion region of EBW joints of Inconel 625 in the as-welded condition Fig. 7 SEM images and EDS analyses showing the elemental composition at different spots (a) nail head region and (b) weld centre of the EB welded Inconel 625 in the PWHT condition 
Fig. 8 EBSD analysis depicting (a) Original (b) IPF and (c) Phase map on the weld region of Incoloy 625 joints after aging for $100 \mathrm{~h}$

Fig. 9 EBSD analysis showing (a) average grain size and (b) misorientation angle distribution in the fusion region of EBW joints of Inconel 625 in the PWHT condition

Fig. 10 Hardness profiles of EB weld joints of Inconel 625 in the as-welded and PWHT conditions

Fig. 11 (a) Tensile tested samples and (b), (c) SEM images showing the fractographic traits of tensile tested EB weld seams of Inconel 625 in the as-welded and PWHT conditions

Fig. 12 SEM images showing the fractographic traits of notch impact tested EB weld seams of Inconel 625 in the (a) as-welded and (b) PWHT conditions

\section{Supplementary File}

Fig. S1 CAD model depicting the samples extracted from EBW joints of Inconel 625 for analysing metallurgical and mechanical characteristics

\section{List of Tables}

Table 1 Chemical composition of base alloy Inconel 625

Table 2 EB welding Process specifications of Inconel 625

Table 3 Vickers micro-hardness data of EB weld seams of Inconel 625

Table 4 Mechanical properties of EB welds of Inconel 625 
Click here to access/download;Figure(s);Fig. 1 Microstructure of the base alloy.docx $\underline{\underline{*}}$

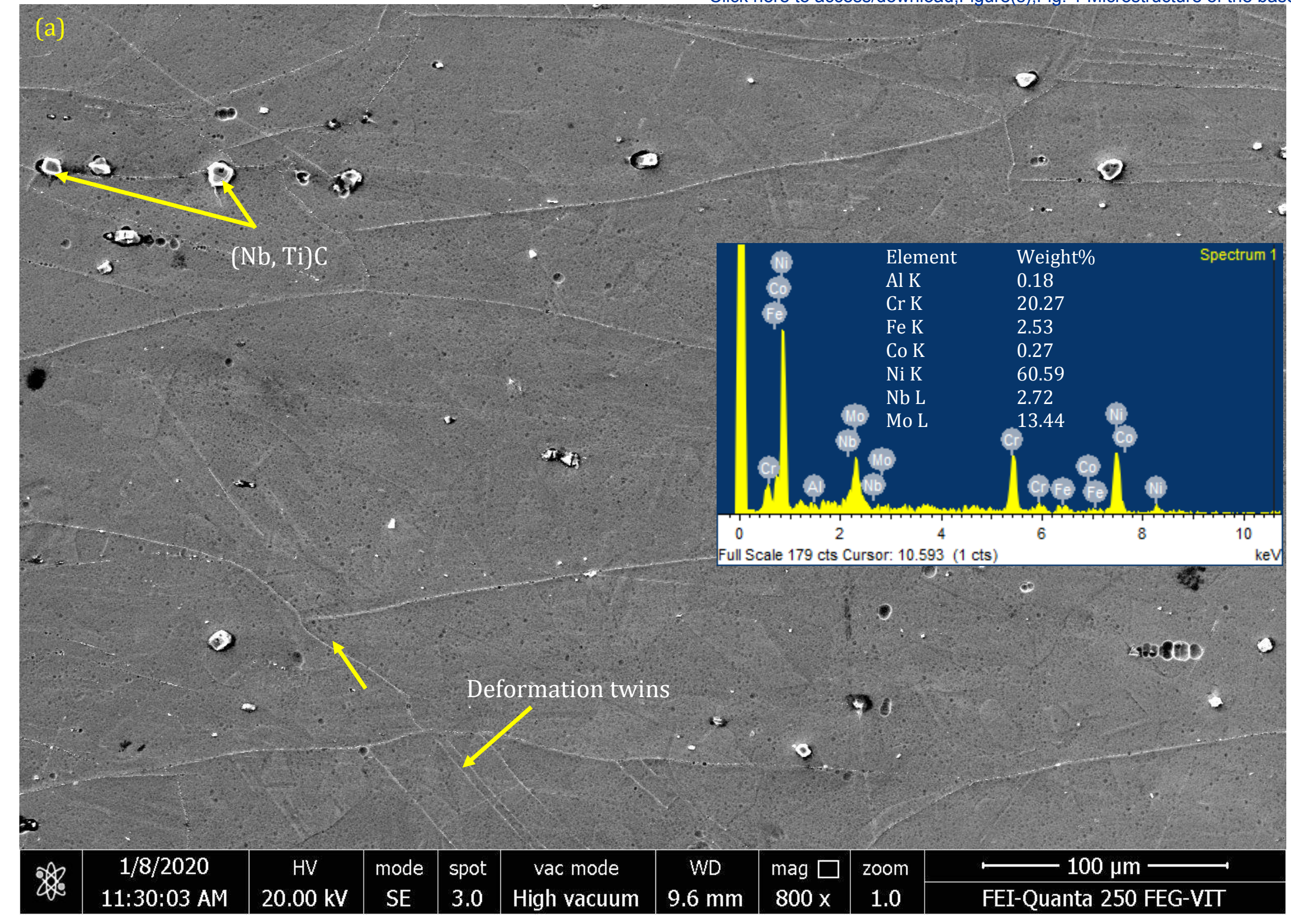

(a) 


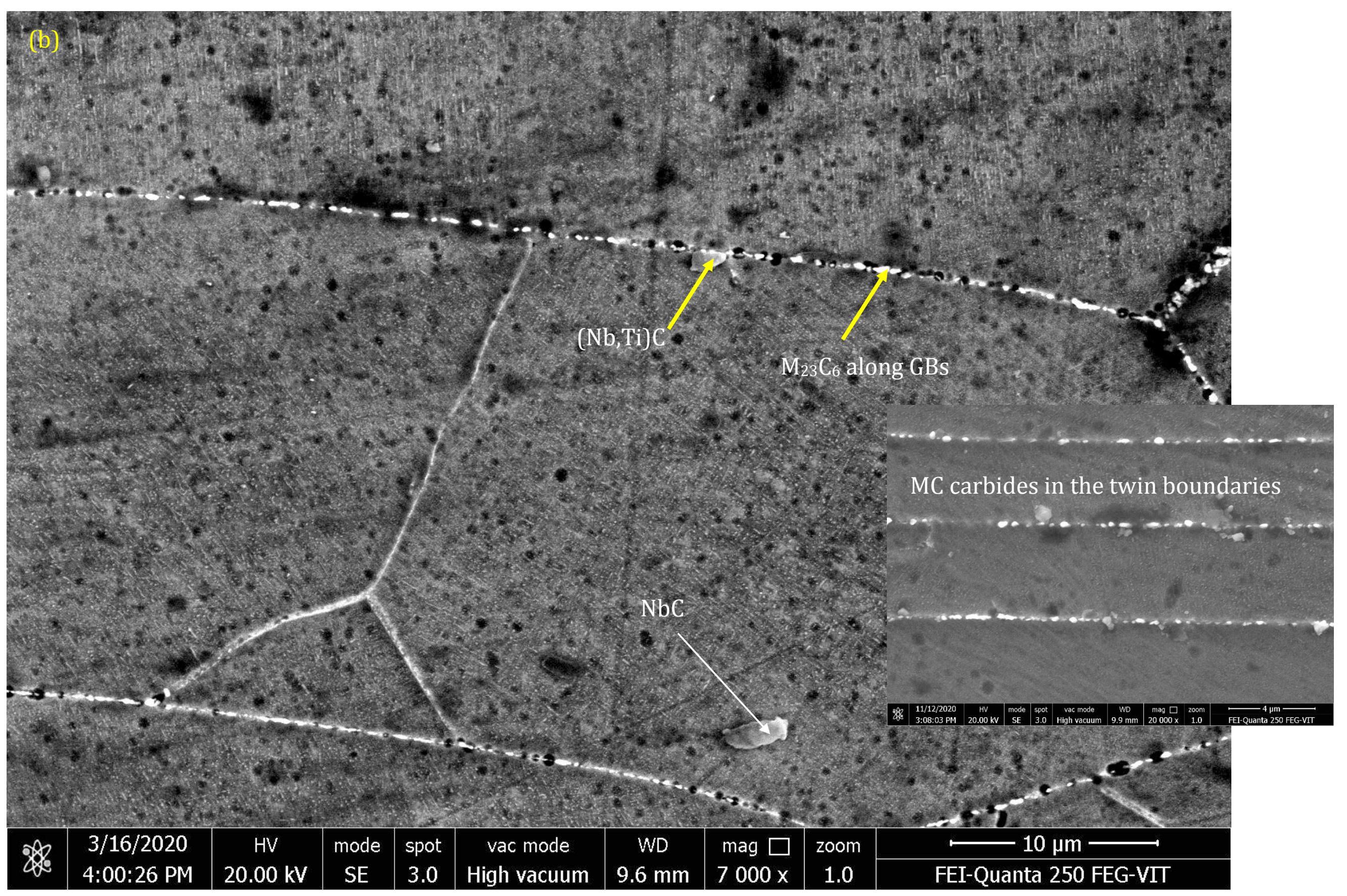

Fig. 1 Microstructure of the base alloy Inconel 625 in the (a) as-received and (b) after subjecting to direct ageing treatment respectively 
BM- Inconel 625

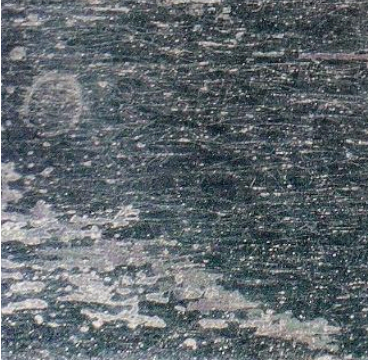

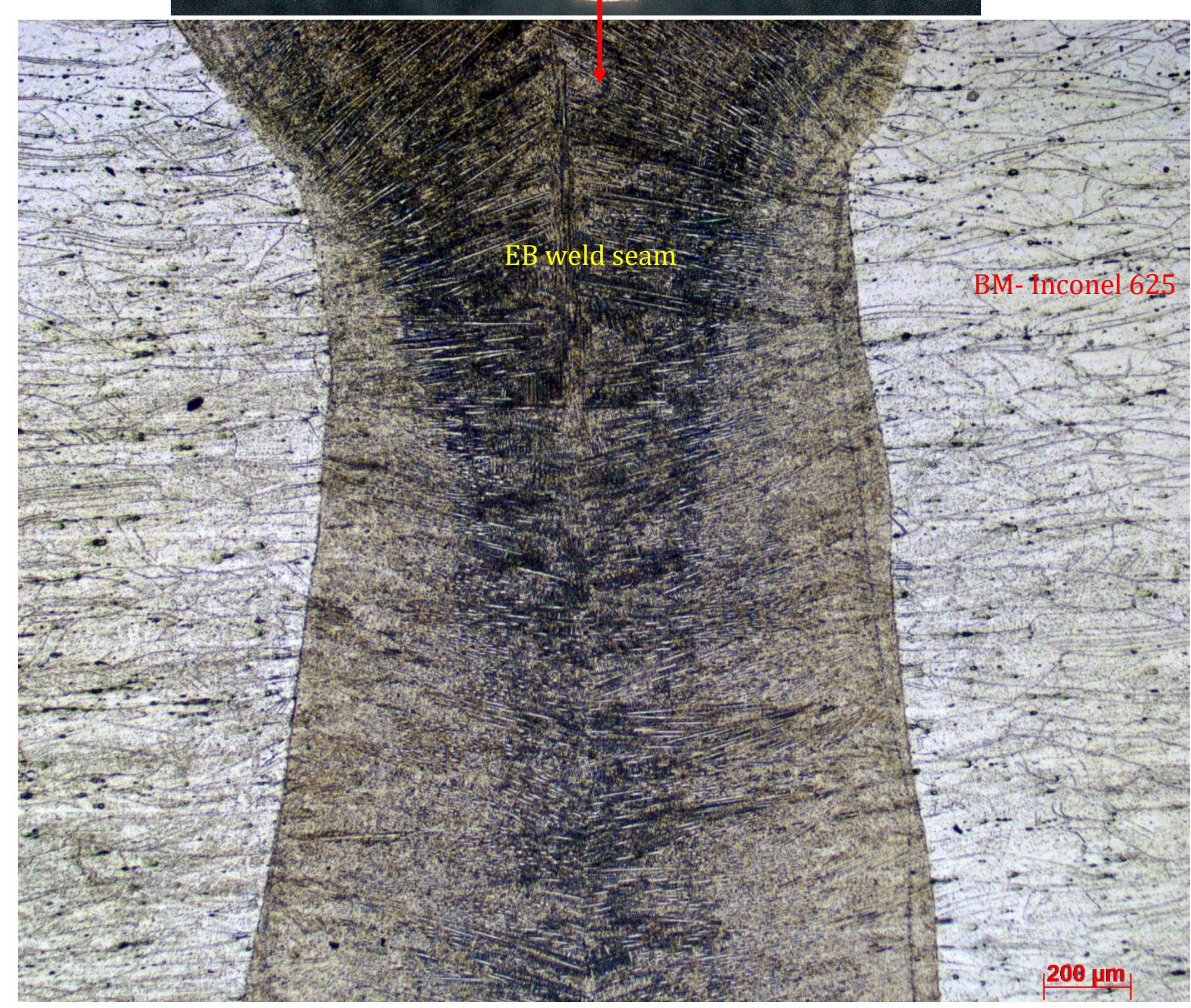

Fig. 2 Cross-sectional macrographs showing the EB weld seams of Inconel 625

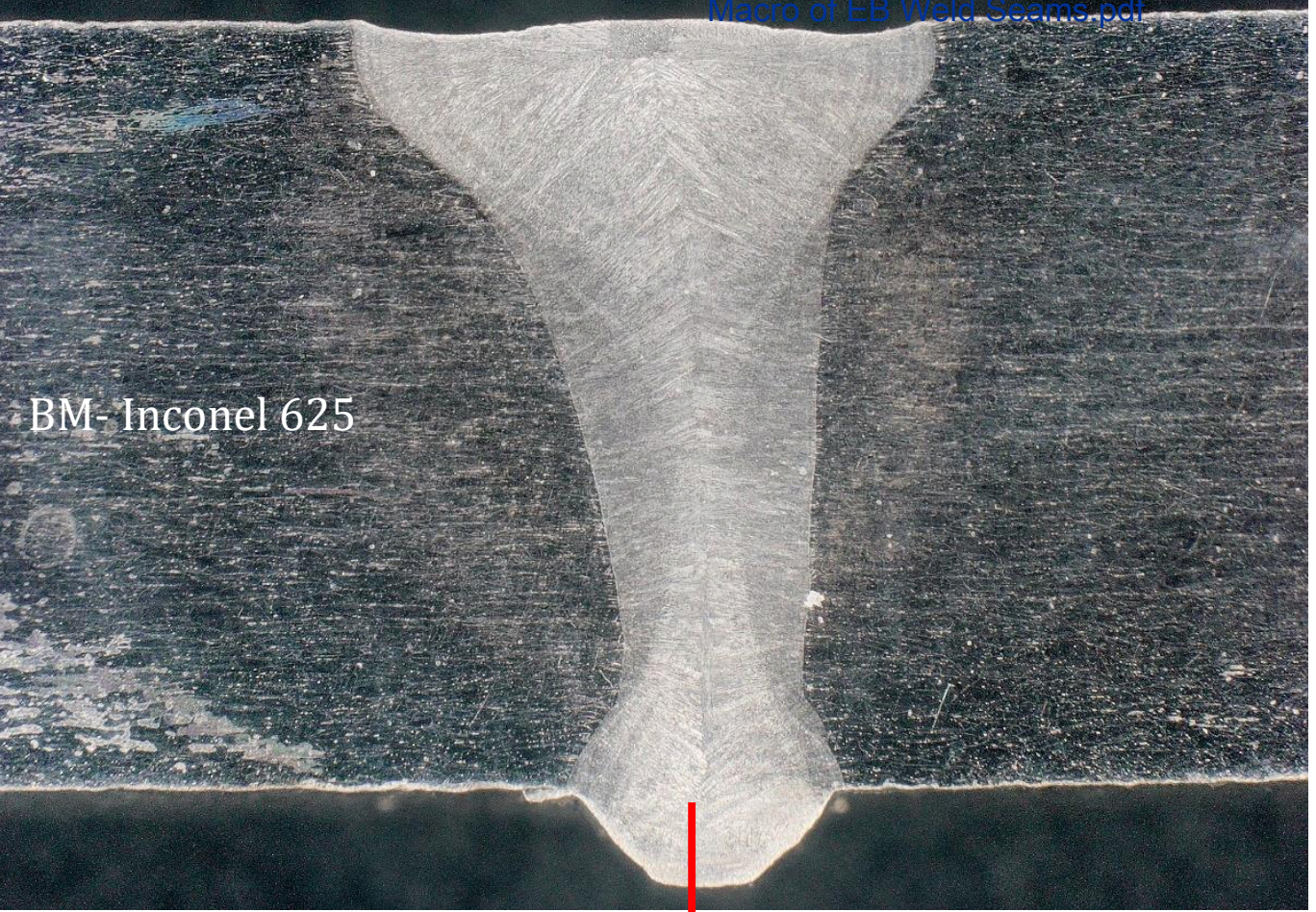




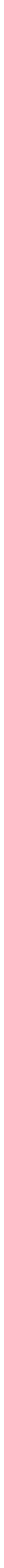




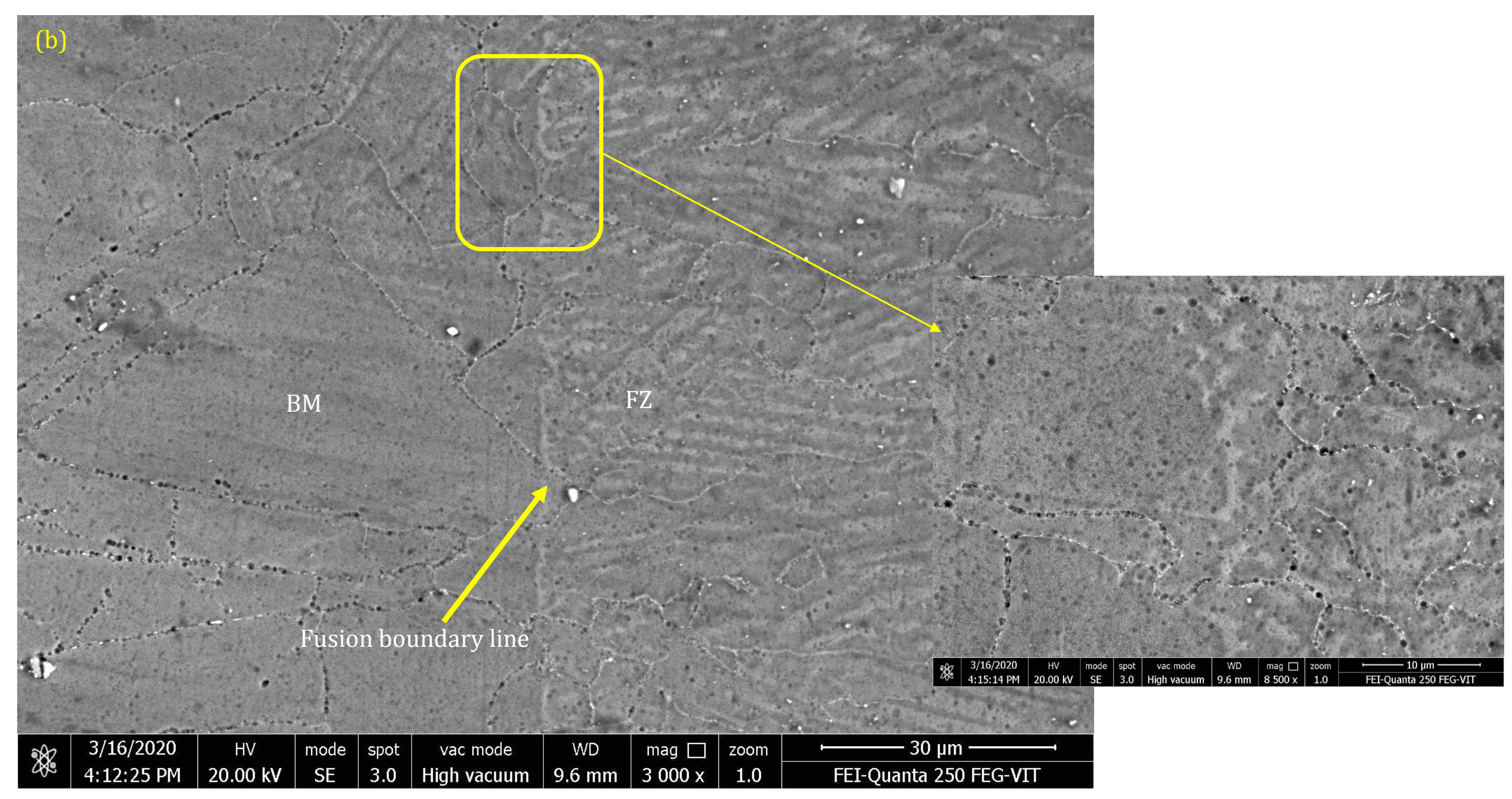

Fig. 3 SEM images showing the interface microstructures of EBW seams of Inconel 625 in the (a) as-welded and (b) direct aged conditions 


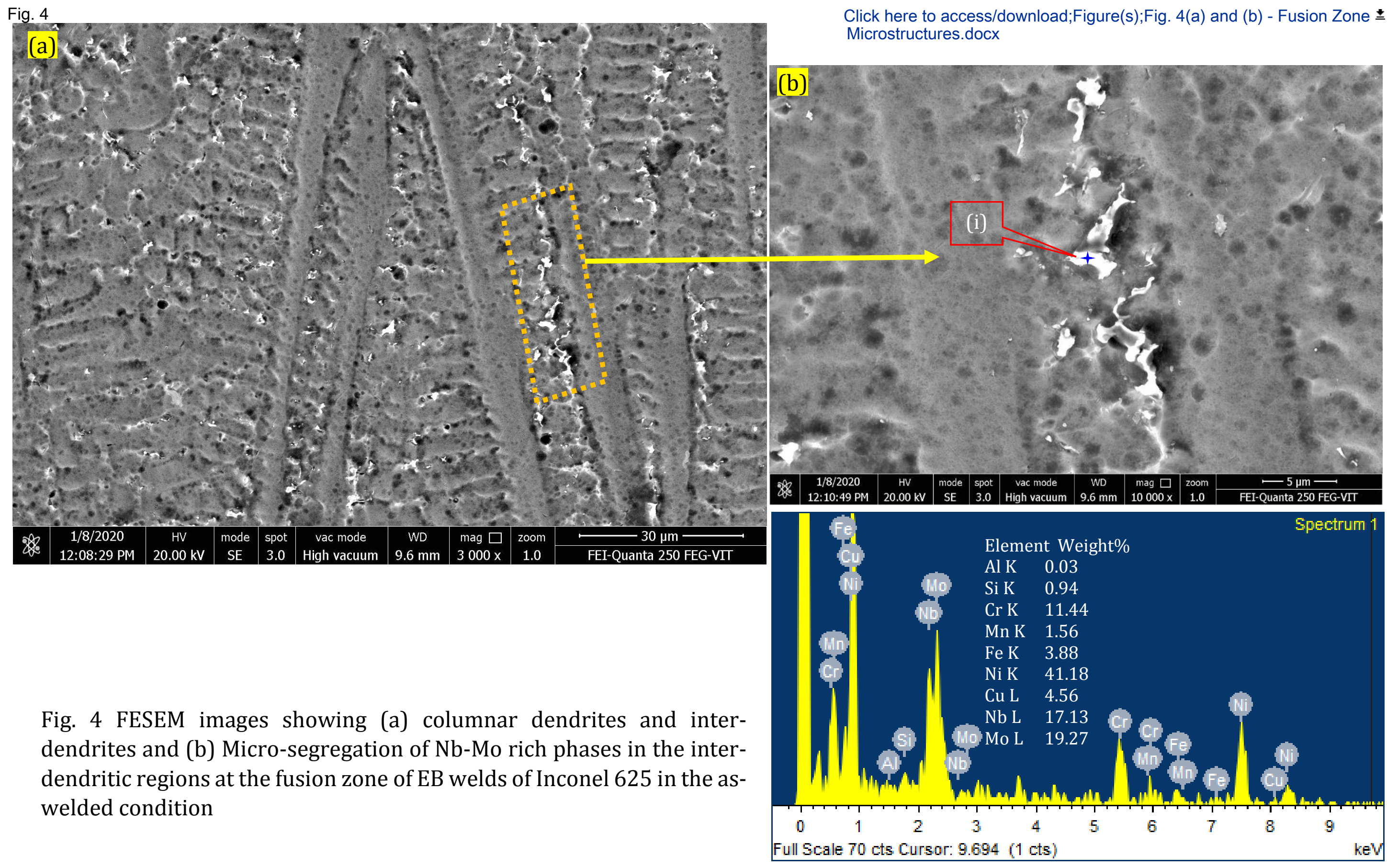



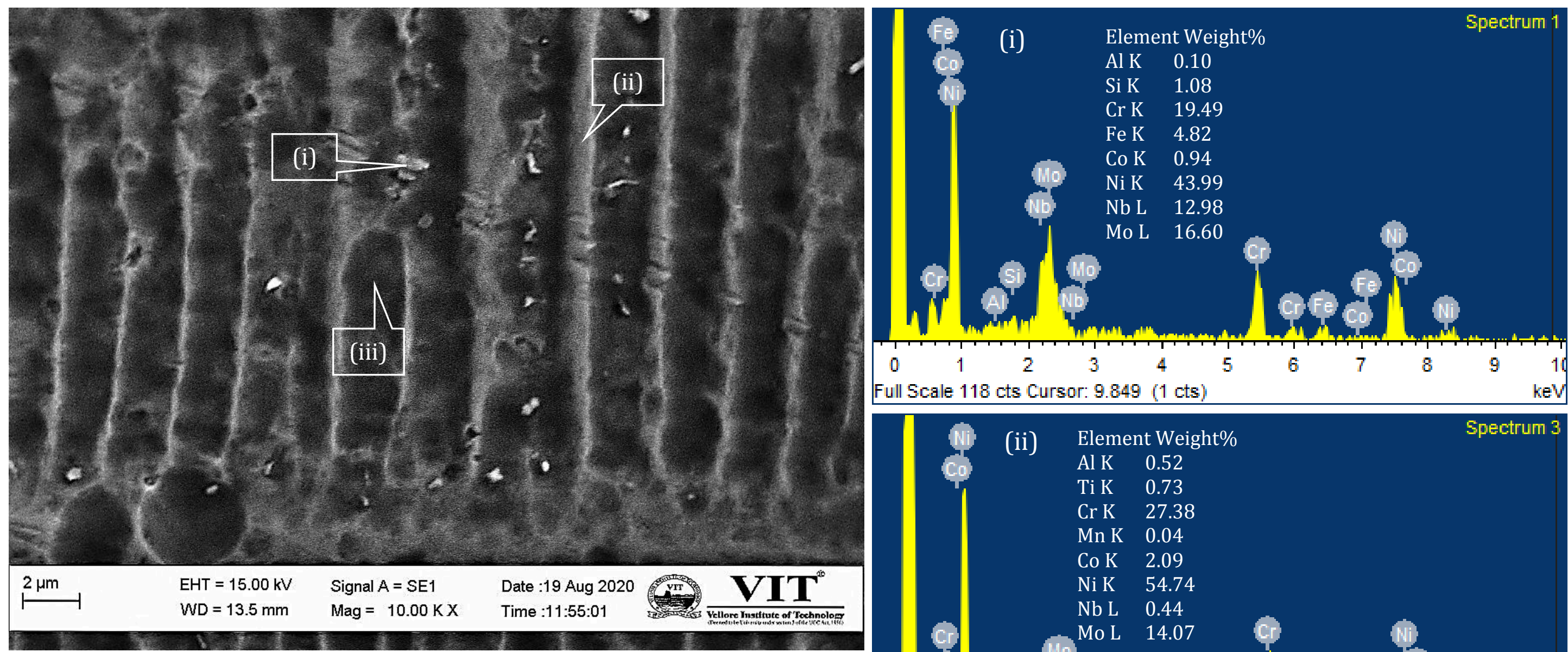

Full Scale 118 cts Cursor: 9.849 (1 cts)

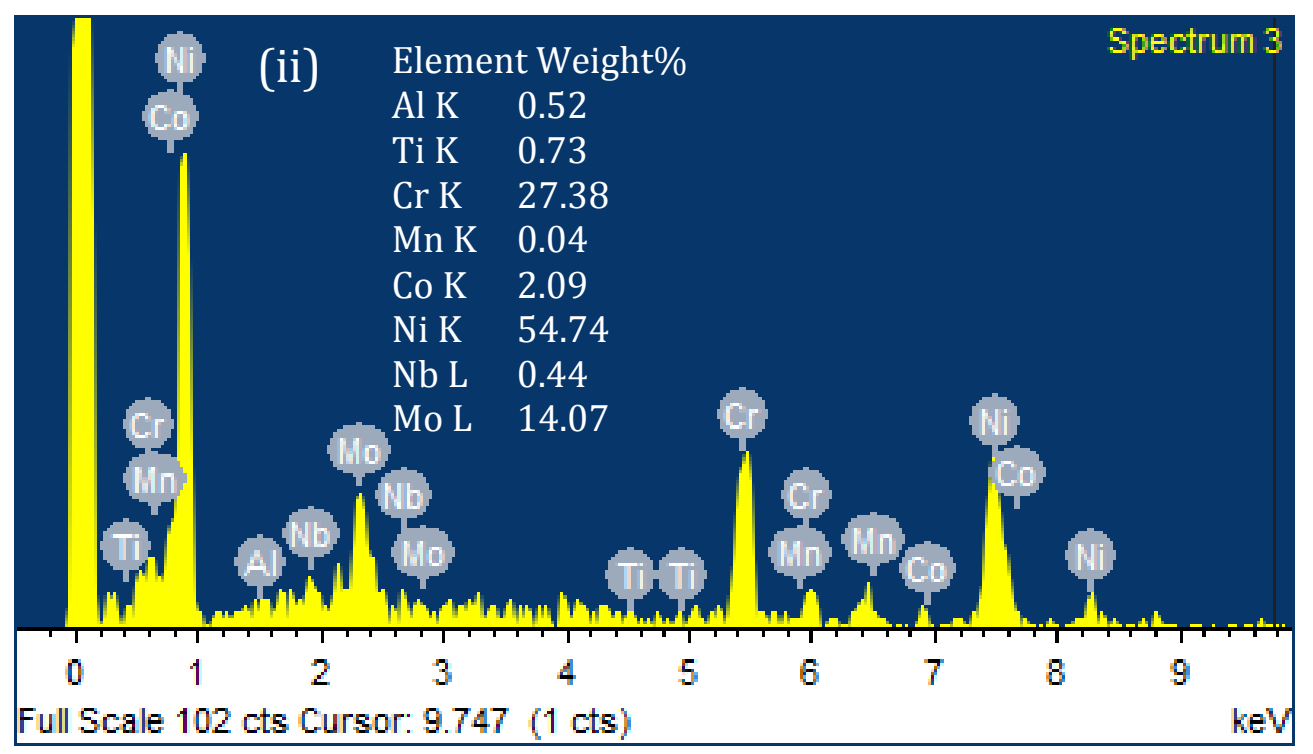

Fig. 4(b) EDS analysis showing the elemental composition at different spots in the fusion region of EB welded Inconel 625 in the as-welded condition 


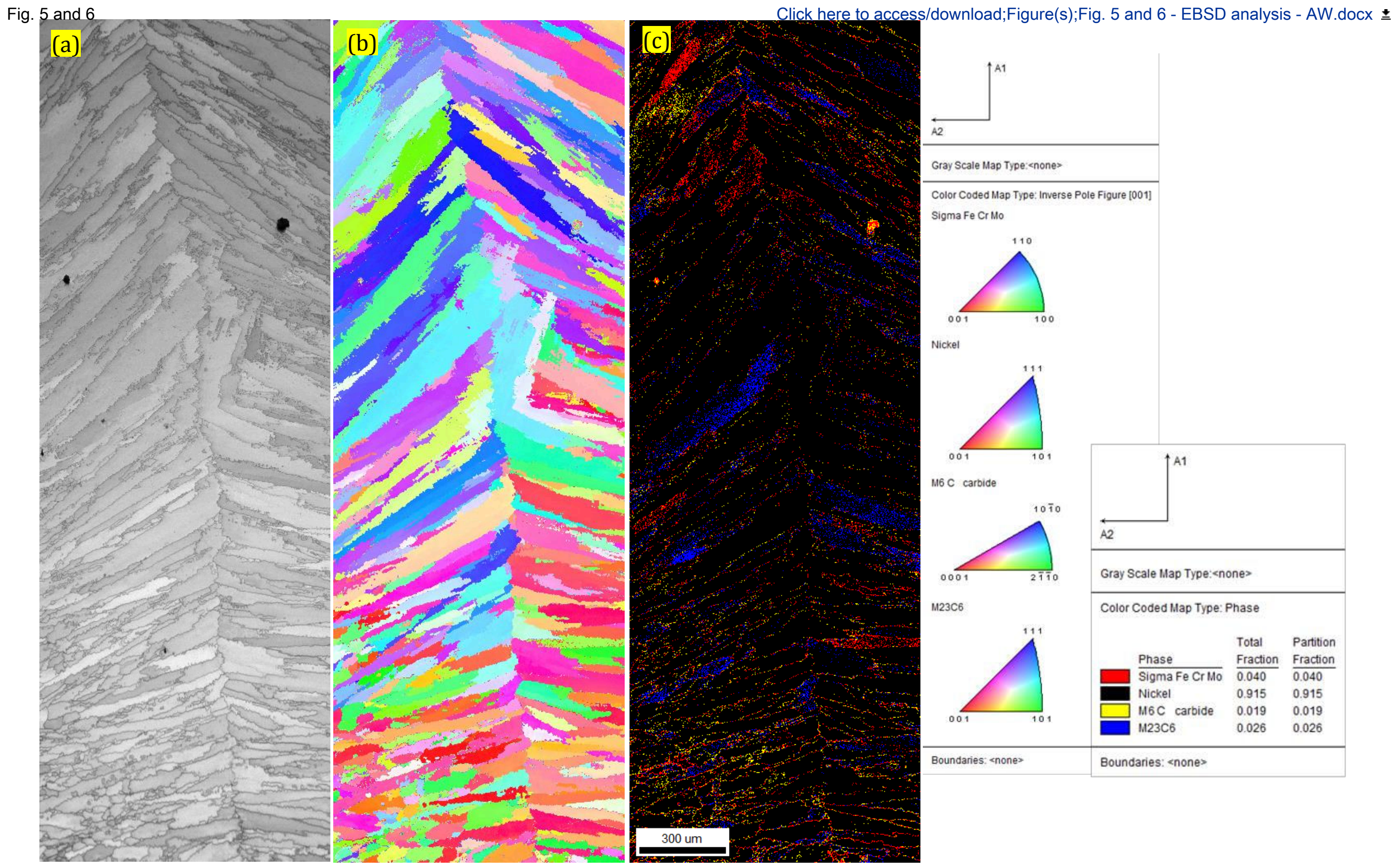

Fig. 5 EBSD analysis depicting (a) Original (b) IPF and (c) Phase map on the weld region of Incoloy 625 joints in the as-welded condition 

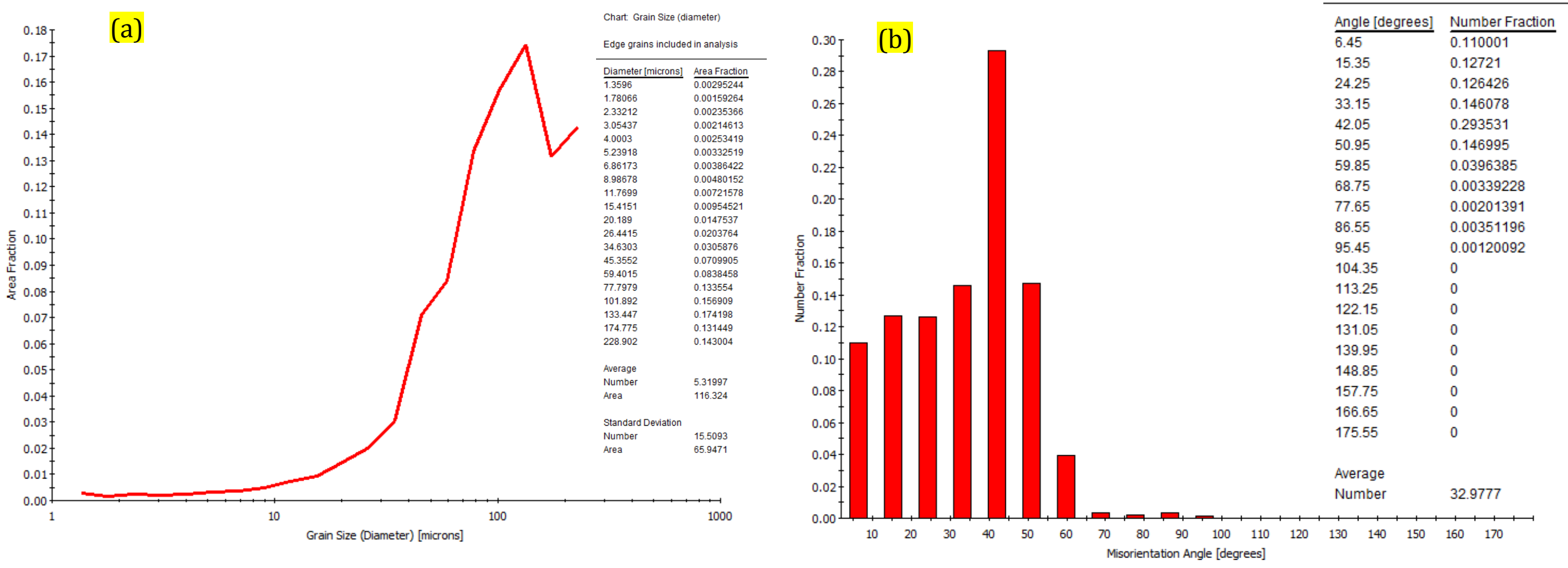

Fig. 6 EBSD analysis showing (a) average grain size and (b) misorientation angle distribution in the fusion region of EBW joints of Inconel 625 in the as-welded condition 


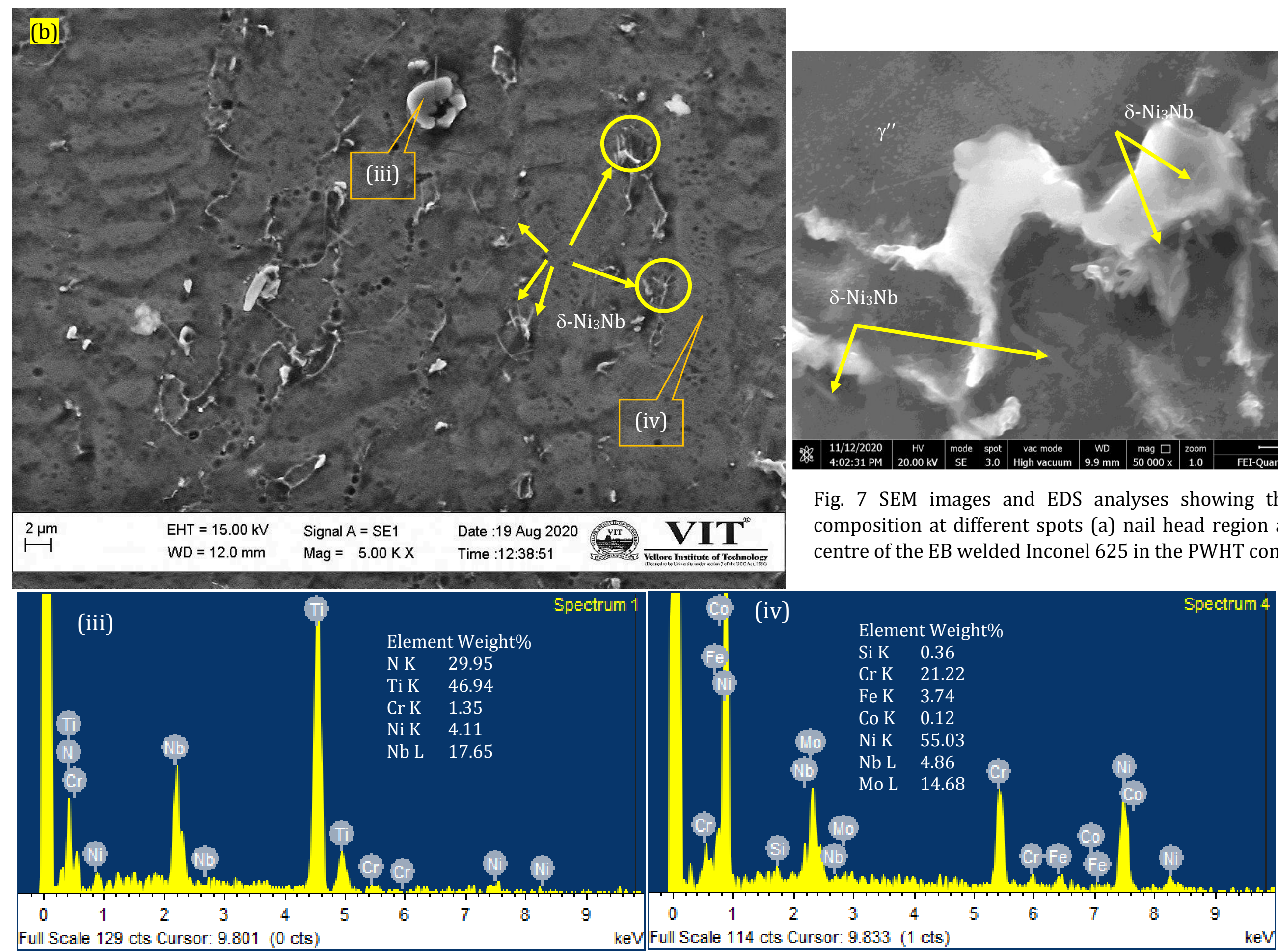



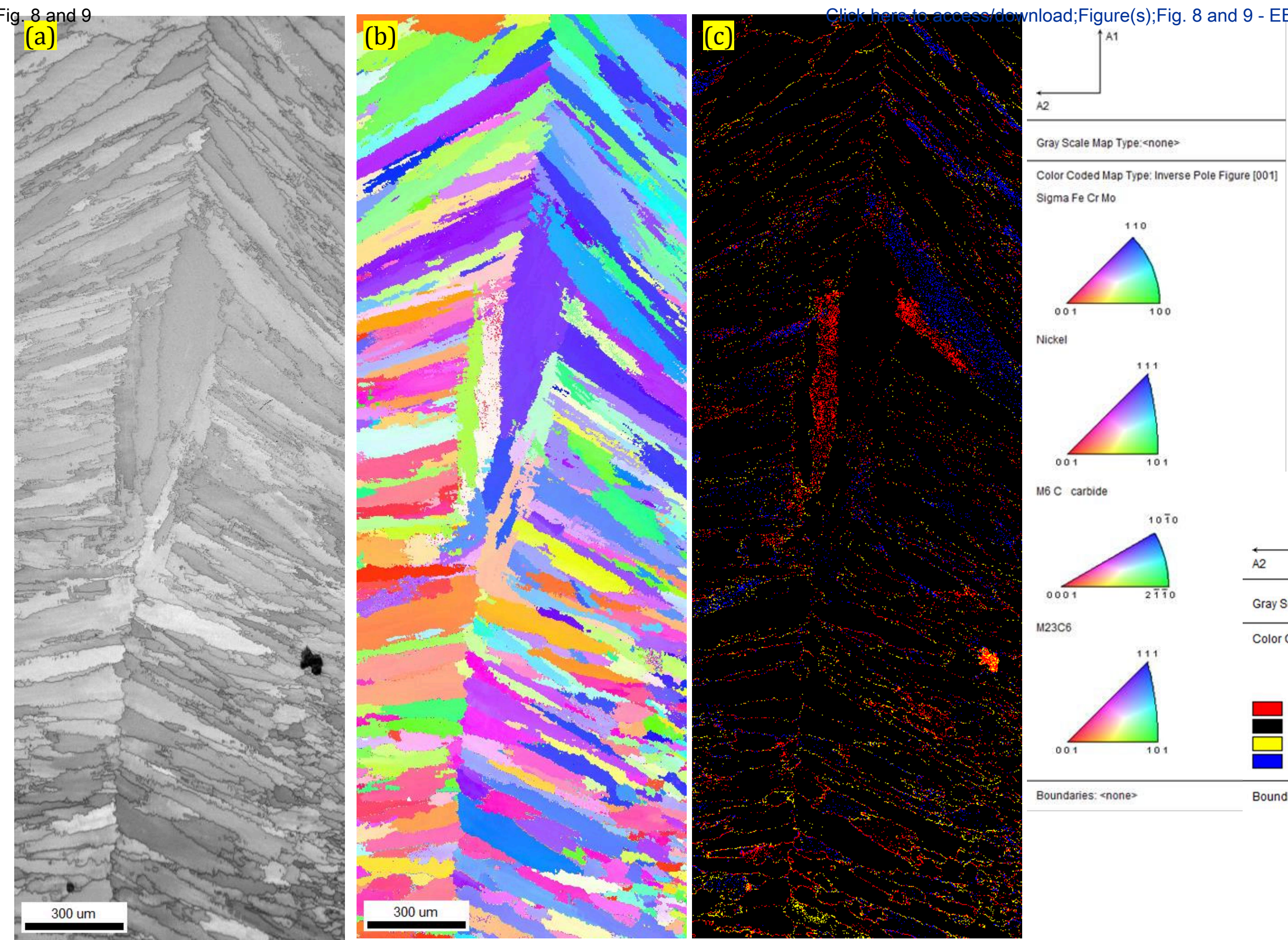

Color Coded Map Th

Sigma Fe CrMo

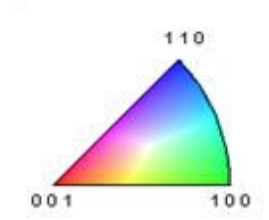

Nickel

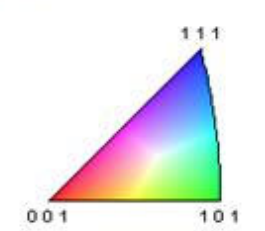

M6 C carbide
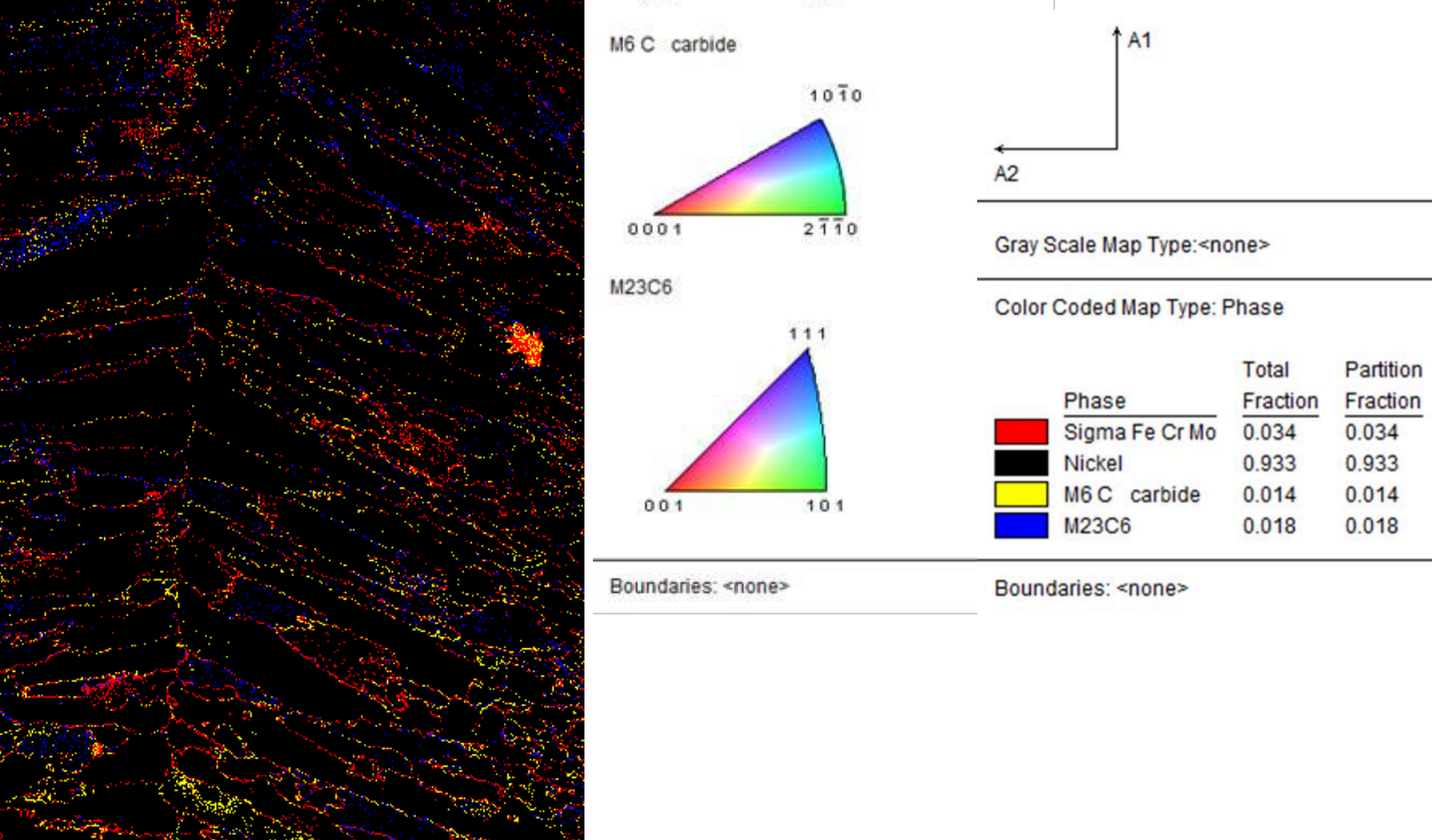

M23C6

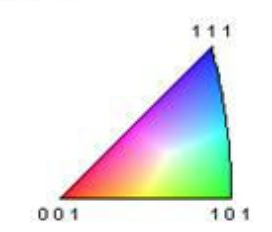

Gray Scale Map Type:<none>

Color Coded Map Type: Phase

Boundaries: <nones

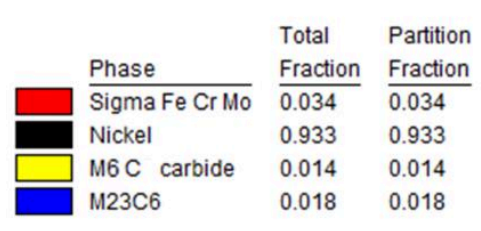

Boundaries: <none>

Fig. 8 EBSD analysis depicting (a) Original (b) IPF and (c) Phase map on the weld region of Incoloy 625 joints after ageing for $100 \mathrm{~h}$ 
(a)

Chart. Grain Size (diameter)

Edge grains included in analysis

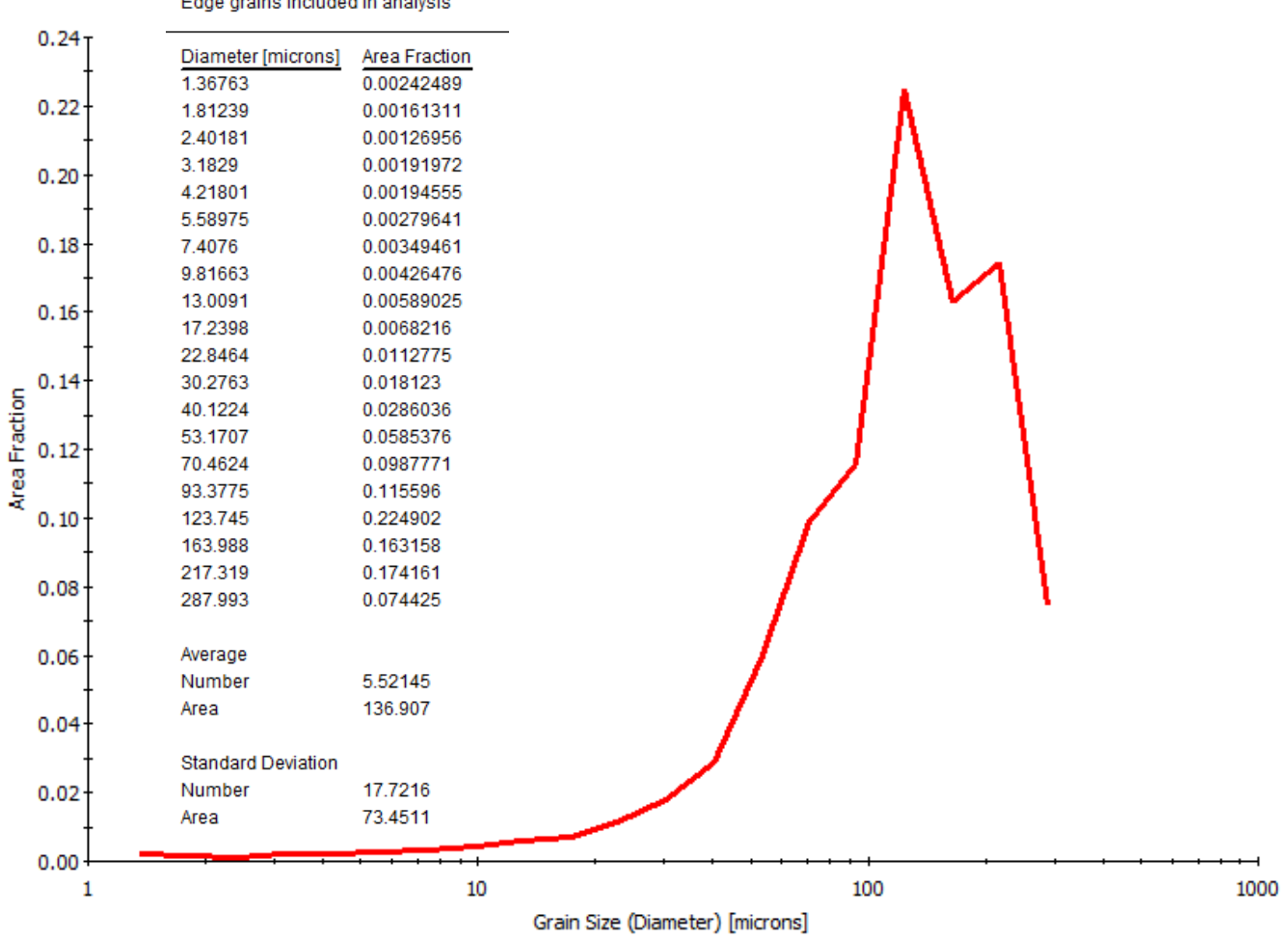

(b)

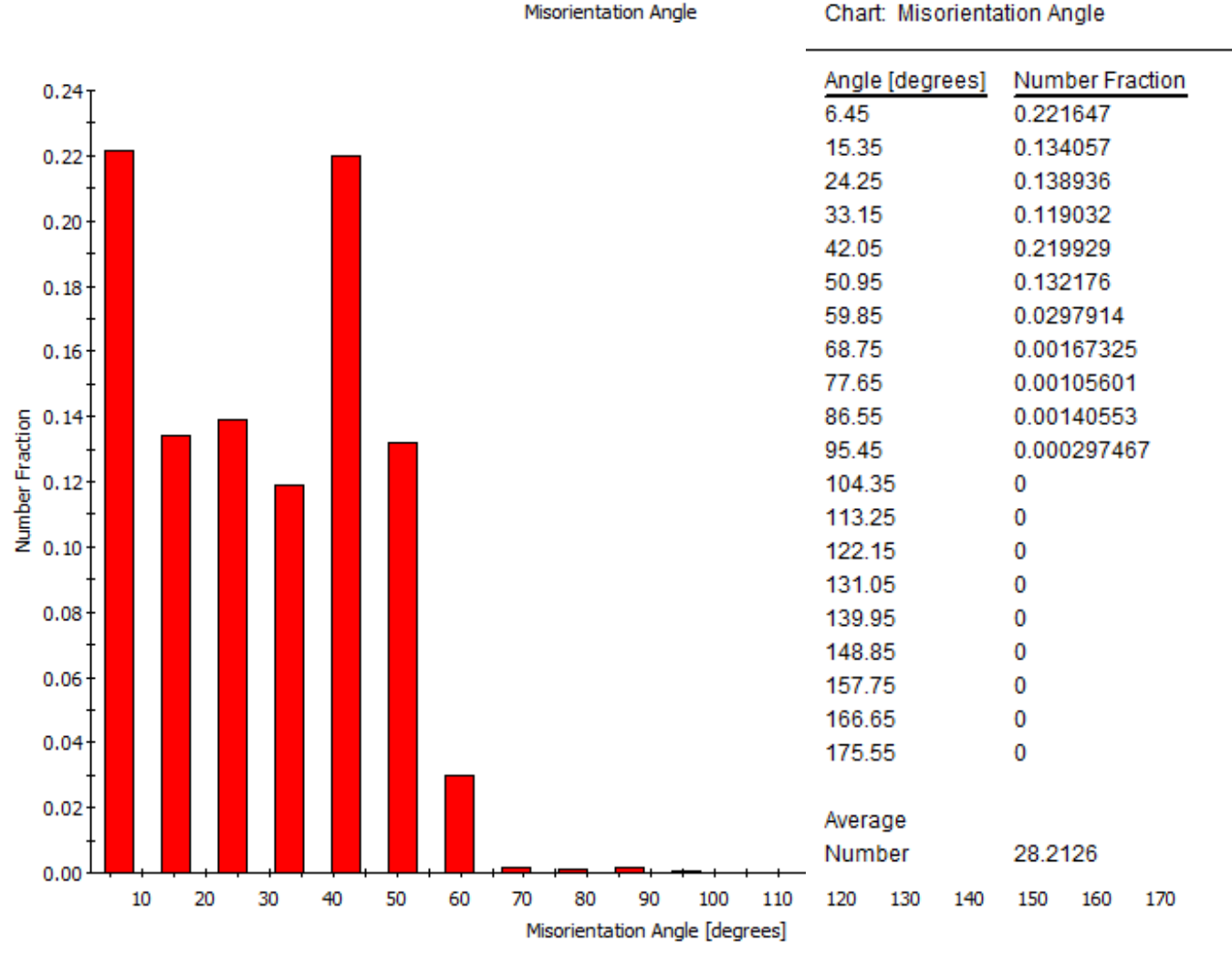

Fig. 9 EBSD analysis showing (a) average grain size and (b) misorientation angle distribution in the fusion region of EBW joints of Inconel 625 in the PWHT condition 


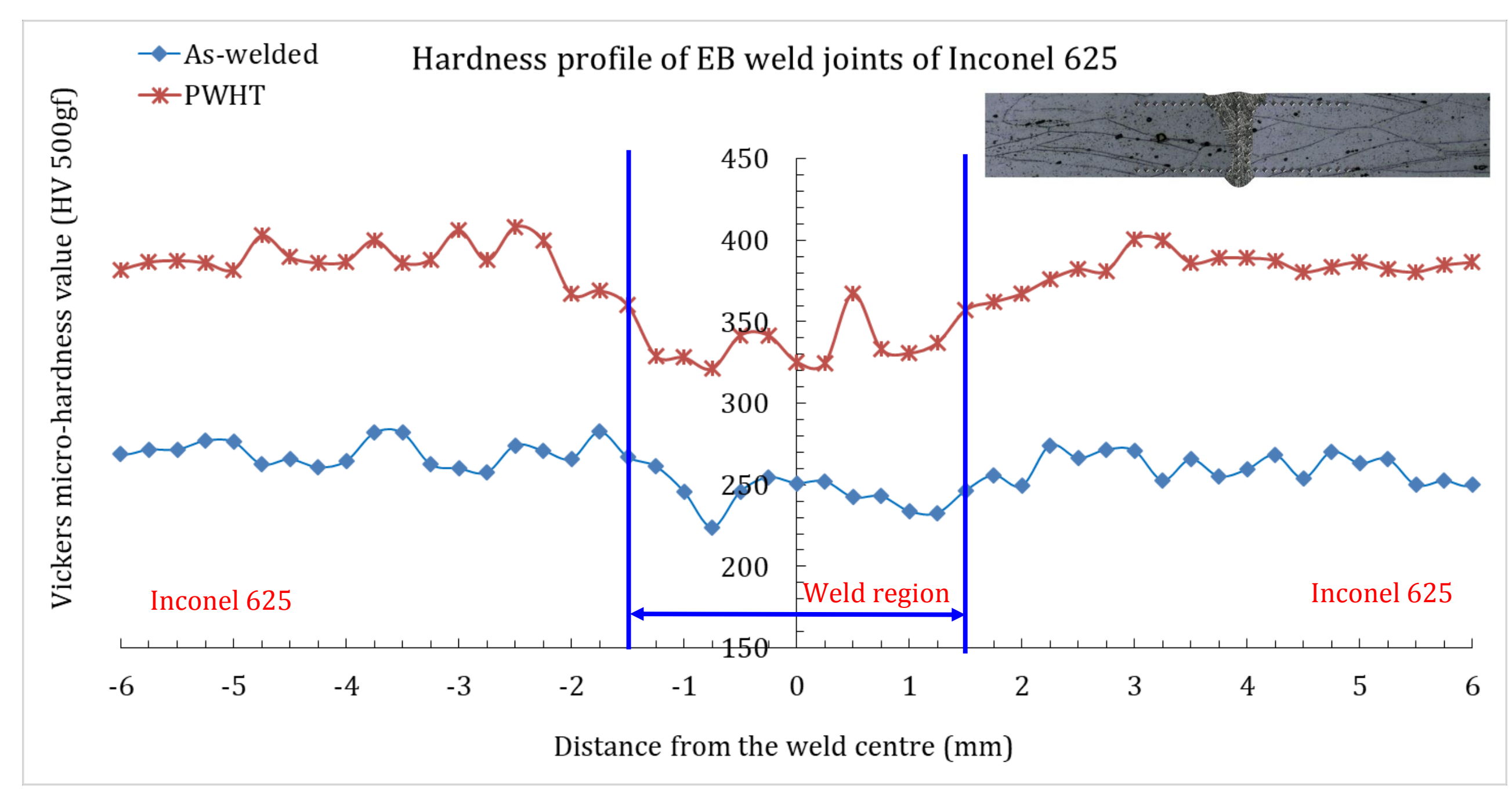

Fig. 10 Hardness profiles of EB weld joints of Inconel 625 in the as-welded and PWHT conditions 


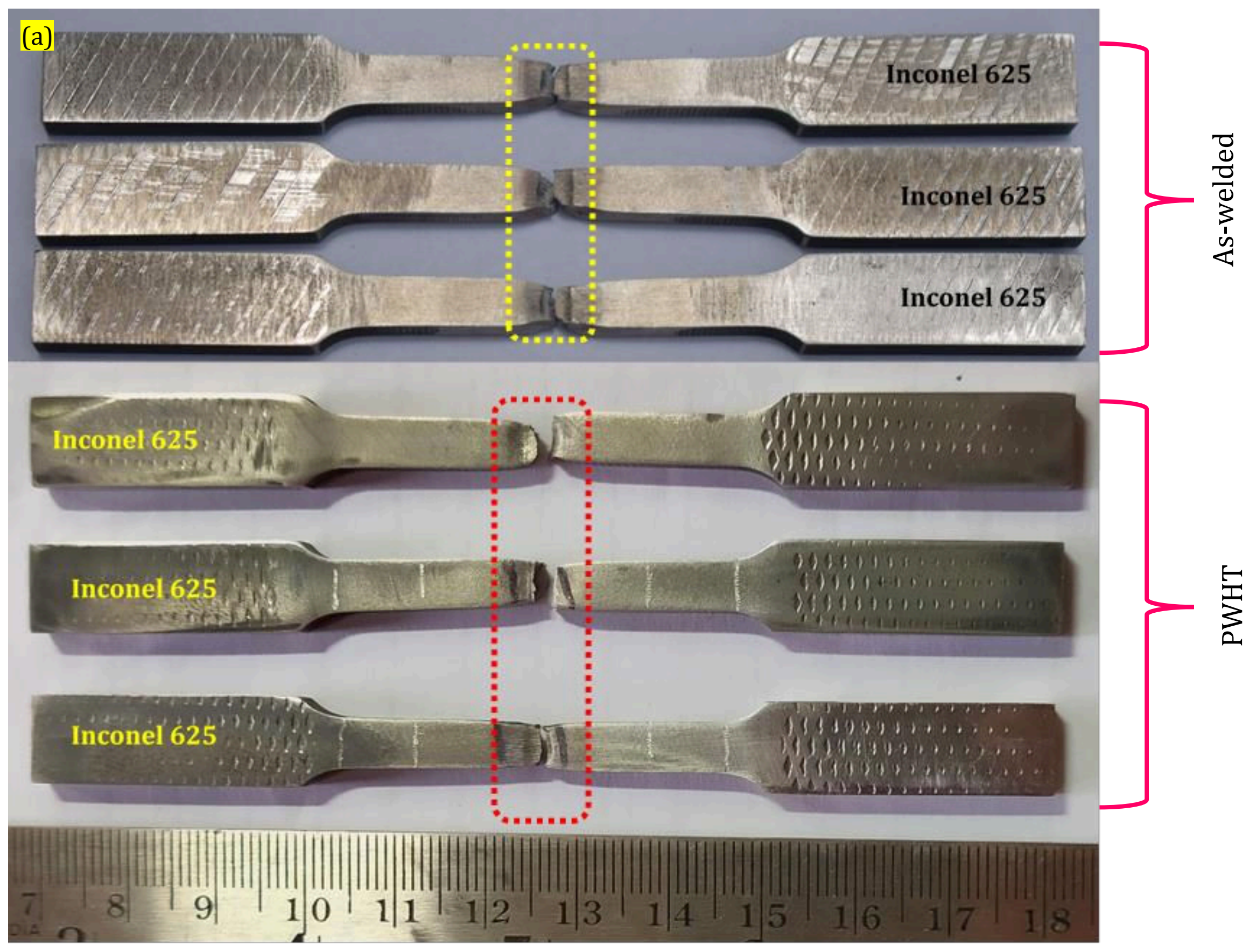




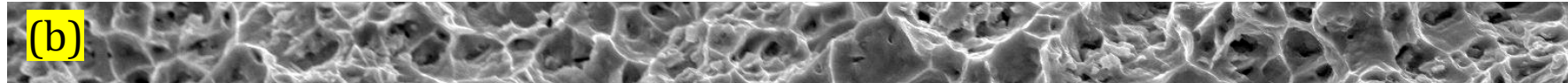

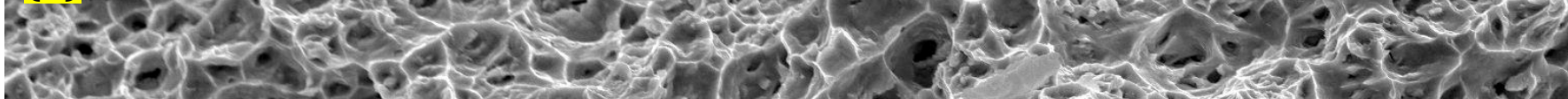

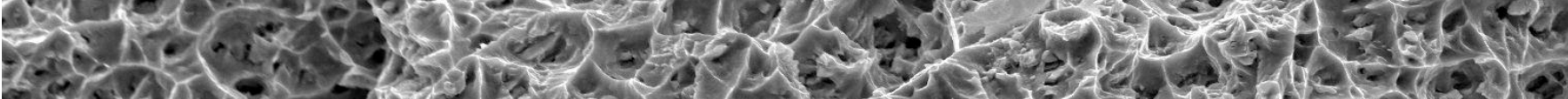

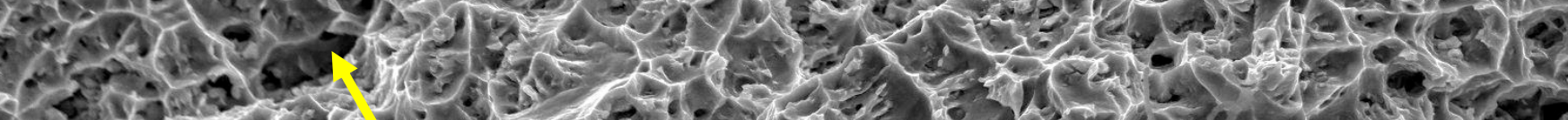

(4.13 क

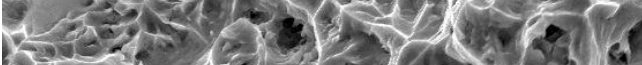

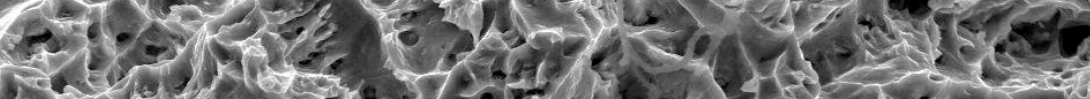

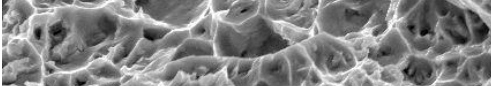

F.

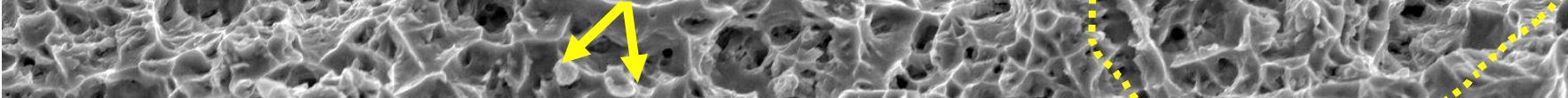
1.5.

\begin{tabular}{c|c|c|c|c|c|c|c|c|c} 
\& & $12 / 19 / 2019$ & HV & mode & spot & vac mode & WD & mag $\square$ & zoom & $\longmapsto$ \\
\cline { 7 - 9 } & $12: 38: 05 \mathrm{PM}$ & $20.00 \mathrm{kV}$ & $\mathrm{SE}$ & 2.5 & High vacuum & $11.2 \mathrm{~mm}$ & $4000 \mathrm{x}$ & 1.0 & FEI-Quanta $250 \mathrm{FEG}$-VIT
\end{tabular}

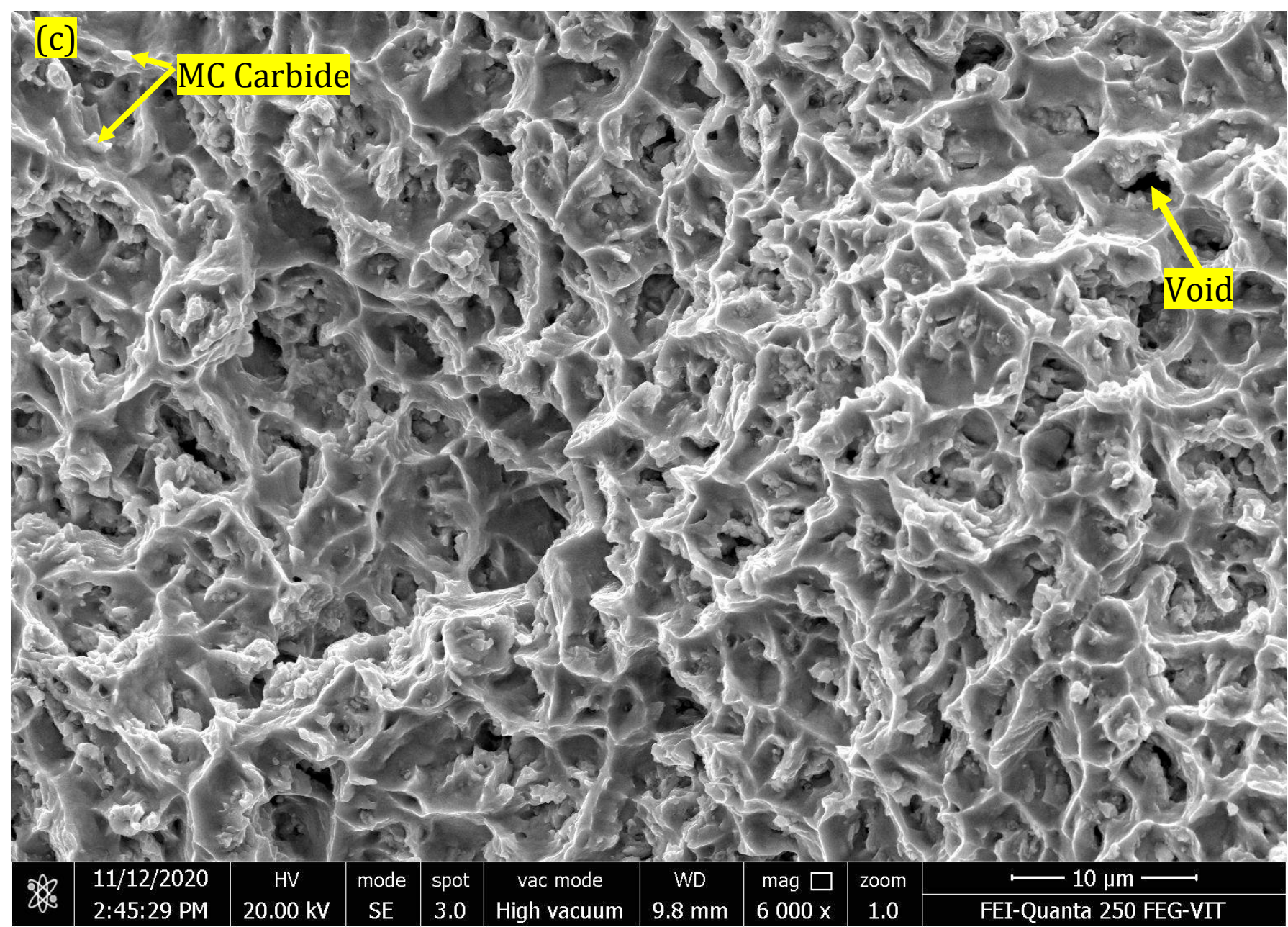

Fig. 11 (a) Tensile tested samples and (b), (c) SEM images showing the fractographic traits of tensile tested EB weld seams of Inconel 625 in the as-welded and PWHT conditions 

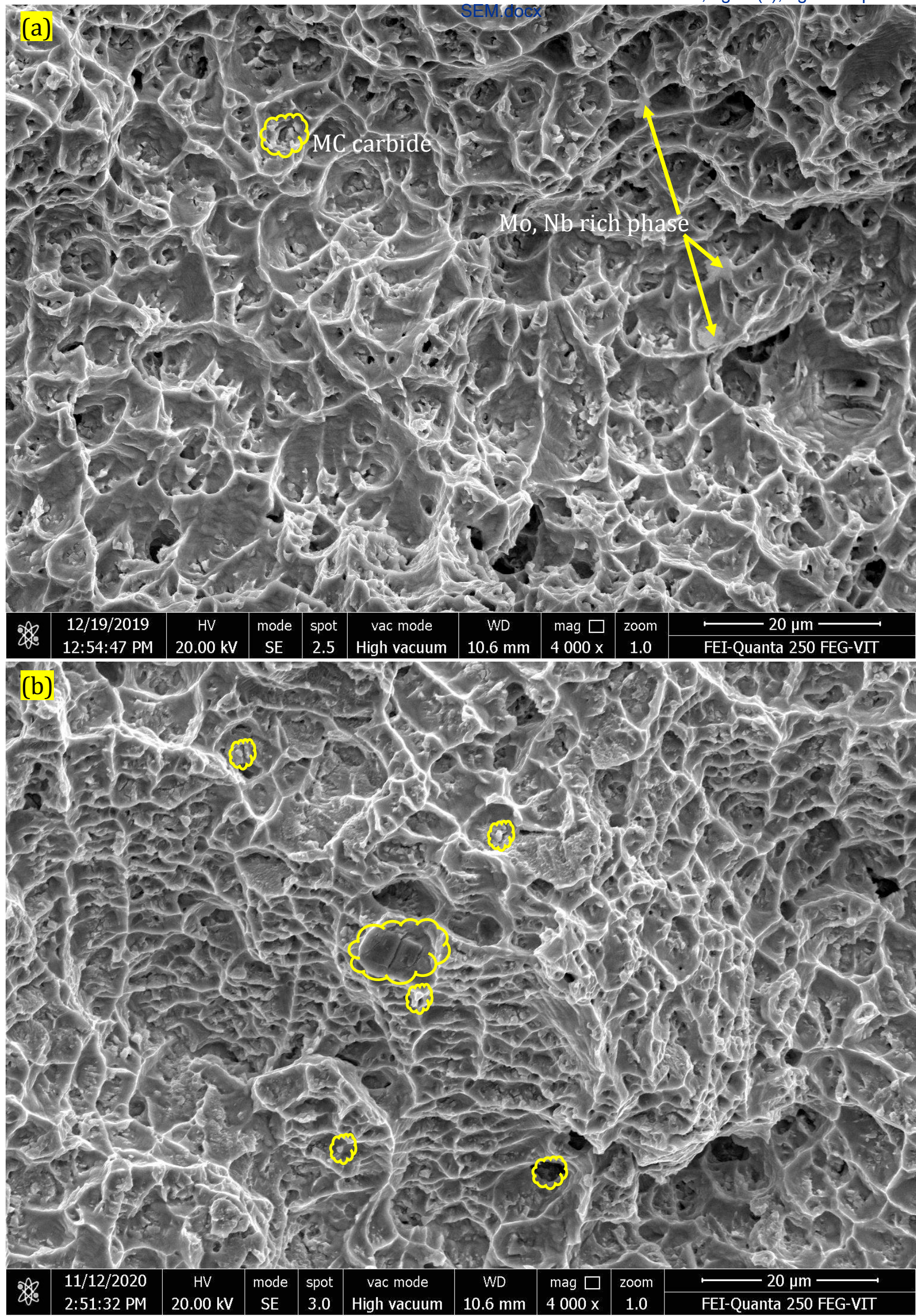

Fig. 12 SEM images showing the fractographic traits of notch impact tested EB weld seams of Inconel 625 in the (a) as-welded and (b) PWHT conditions 
Table 1 Chemical composition of base alloy Inconel 625

\begin{tabular}{lcccccccc} 
Base Metal & \multicolumn{9}{c}{ Composition (\% Weight) } \\
\cline { 2 - 9 } Inconel 625 & $\mathbf{C}$ & $\mathbf{M n}$ & $\mathbf{C r}$ & $\mathbf{M o}$ & $\mathbf{F e}$ & $\mathbf{N b}$ & $\mathbf{N i}$ & Others \\
& 0.031 & 0.091 & 22.24 & 9.038 & 4.38 & 3.531 & Rem. & $\mathrm{P}-0.004 ; \mathrm{S}-0.001 ; \mathrm{Si}-0.167 ; \mathrm{Al}-$ \\
& & & & & & & & $0.207 ; \mathrm{Ti}-0.290 ; \mathrm{Co}-0.098$
\end{tabular}


Table 2 EB welding Process specifications of Inconel 625

\begin{tabular}{llll}
\hline Parameter & & Unit & Value \\
\hline Welding Current & $:$ & $\mathrm{mA}$ & 100 \\
\hline Voltage & $:$ & $\mathrm{kV}$ & 60 \\
\hline Vacuum Level & $:$ & $\mathrm{mbar}$ & $10^{-4}$ to $10^{-5}$ \\
\hline Welding Speed & $:$ & $\mathrm{mm} / \mathrm{min}$ & 1500 \\
\hline Heat Input & $:$ & $\mathrm{kJ} / \mathrm{mm}$ & 0.24 \\
\hline Weld bead quality check & $:$ & -- & X-ray Radiography \\
\hline Weld Penetration & $:$ & --- & Full \\
\hline
\end{tabular}

Table 3 Vickers micro-hardness data of EB weld seams of Inconel 625

\begin{tabular}{lccc}
\hline \multirow{2}{*}{ Location } & \multicolumn{2}{c}{ Micro-hardness value (HV 500gf) } & \multirow{2}{*}{ \% increase in hardness } \\
\cline { 2 - 3 } & As-welded & PWHT & \\
\hline Base Metal Side & 266 & 388 & 45.67 \\
\hline EB Weld Region & 246 & 334 & 35.77 \\
\hline
\end{tabular}


Table 4 Mechanical properties of EB welds of Inconel 625

\begin{tabular}{|c|c|c|c|c|c|}
\hline \multirow[t]{2}{*}{ Mechanical Property } & \multirow[t]{2}{*}{ Unit } & \multirow{2}{*}{$\begin{array}{l}\text { Base alloy } \\
\text { As-received }\end{array}$} & \multirow[b]{2}{*}{ PWHT } & \multicolumn{2}{|c|}{ EB weld seams } \\
\hline & & & & As-welded & PWHT \\
\hline $0.2 \%$ offset Yield strength & $\mathrm{MPa}$ & $494.3 \pm 5.5$ & $794.5 \pm 8.5$ & $565.4 \pm 6.5$ & $671.5 \pm 4.6$ \\
\hline Tensile strength & $\mathrm{MPa}$ & $879.7 \pm 4.2$ & $1111 \pm 6.6$ & $858.4 \pm 8.4$ & $1,011 \pm 9.1$ \\
\hline Joint Efficiency & $\%$ & --- & --- & 97.53 & $90.99 \%$ \\
\hline$\%$ Elongation & $\%$ & $53.5 \pm 1.2$ & 34 & $34.5 \pm 2.2$ & $29.0 \pm 1.8$ \\
\hline Fracture location & --- & ---- & ---- & Weld & Weld \\
\hline Impact toughness & $\mathrm{J}$ & $41 \pm 4.0$ & 22 & $57 \pm 3.5$ & 28 \\
\hline Physical Observation of impact tested sample & --- & $\begin{array}{c}\text { V-notch } \\
\text { deformation }\end{array}$ & $\begin{array}{l}\text { Broken into two } \\
\text { halves }\end{array}$ & $\begin{array}{l}\text { Broken into two } \\
\text { halves }\end{array}$ & $\begin{array}{l}\text { Broken into two } \\
\text { halves }\end{array}$ \\
\hline
\end{tabular}



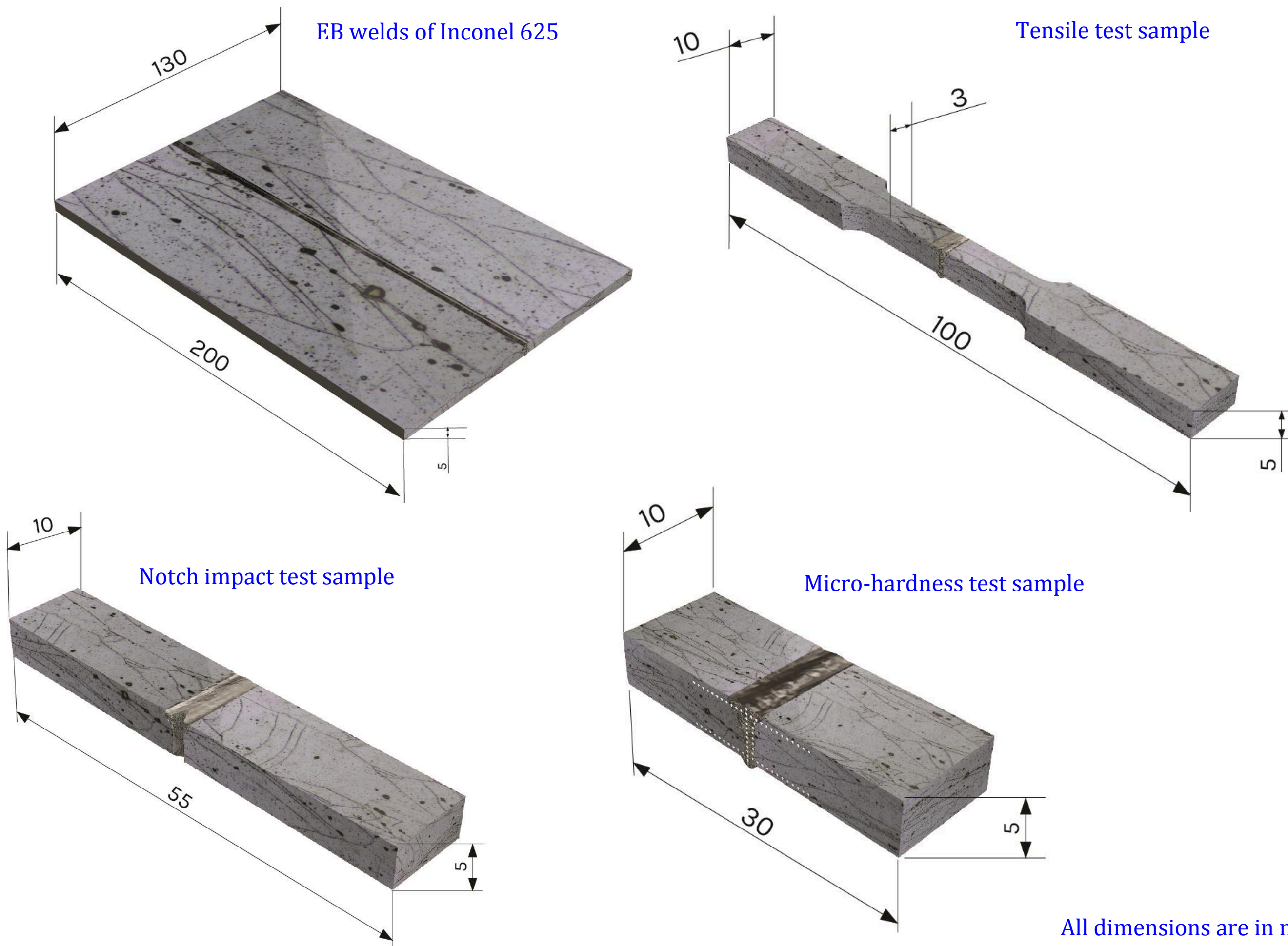


\section{Research Highlights}

- Grain boundary precipitation of MC carbides on EB weld seams of Incoloy 925

- Formation of $\mathrm{M}_{23} \mathrm{C}_{6}, \mathrm{M}_{6} \mathrm{C}$ carbides in the grain boundaries of weld microstructures in both the conditions

- Improved yield and tensile strengths after subjecting to PWHT conditions 


\title{
Effect of grain boundary precipitation on the mechanical integrity of EBW joints of Inconel 625
}

\author{
Ramkumar, K. Devendranath
}

Elsevier

Ramkumar KD, Mulimani SS, Ankit K, et al., (2021) Effect of grain boundary precipitation on the mechanical integrity of EBW joints of Inconel 625. Materials Science and Engineering A:

Structural Materials: Properties. Microstructures and Processing, Volume 808, March 2021, Article number 140926

https://doi.org/10.1016/j.msea.2021.140926

Downloaded from Cranfield Library Services E-Repository 